\title{
Carbon Nanotubes - Imprinted Polymers: Hybrid Materials for Analytical Applications
}

\author{
Giuseppe Cirillo ${ }^{*}$, Silke Hampel2 ${ }^{2}$, Francesco Puoci ${ }^{1}$, \\ Diana Haase 2 , Manfred Ritschel2 ${ }^{2}$, Albrecht Leonhardt², \\ Francesca Iemma ${ }^{1}$ and Nevio Picci ${ }^{1}$ \\ ${ }^{1}$ Department of Pharmaceutical Sciences, University of Calabria, Rende (CS), \\ ${ }^{2}$ Leibniz Institute for Solid State and Materials Research Dresden, Dresden \\ IItaly \\ ${ }^{2}$ Germany
}

\section{Introduction}

Molecular imprinting is a recent new and rapidly evolving technique which allows the creation of synthetic receptors (MIPs) consisting of highly cross-linked porous-rich polymers with recognition properties comparable to the biological systems related to the presence of specific recognition sites complementary in shape, size and functional groups to a target molecule. It is a facile concept, which involves the construction of sites of specific recognition, commonly within synthetic polymers. The template of choice is entrapped within a pre-polymerization complex, consisting of functional monomers with good functionality, which chemically interacts with the template. Polymerization in the presence of crosslinker serves to freeze these template-monomer interactions and subsequent removal of the template results in the formation of a molecularly imprinted polymer matrix. Due to the advantages of MIPs such as low cost, stability, and easy preparation compared with natural molecular recognition products (e.g. antibody), Molecular imprinting is a welldeveloped tool in the analytical field, mainly for separating and quantifying very different substances, including drugs and bio-active molecules contained in relatively complex matrices. Despite the application of MIPs as sensor matrices or separation materials, they suffer from basic limitations associated with the limited concentration of imprinted sites, and the bulk volume of the polymer matrices that requires long diffusion paths of the imprinted host molecules. These limitations lead to inefficient sensing or separation processes. MIP nanomaterials are proposed as a pain reliever for headache by improving the accessibility and the homogeneity of the binding sites. In particular, with high strength, the extremely large surface area and unique chemical properties, Carbon nanotubes (CNTs) could serve as the reinforcing element or core in fabricating core-shell structural MIPs.

Since their discovery in 1991, CNTs have attracted great attention because of their unique properties (high electrical conductivity, chemical stability, mechanical strength, large specific surface area, and high thermal stability) indicating potential for various applications. 
CNTs represent a new carbon material that has been widely recognized as the quintessential nanomaterial and, because the hexagonal arrays of carbon atoms of the CNTs surface have a strong interaction with other molecules or atoms, CNTs show a great analytical potential as a solid-phase extraction adsorbent. Additionally, CNTs' surfaces can be modified by introducing various organic functional groups, thus providing a strongly physic sorbing surface area, adjustable surface charge, and a source of protons for chemical ionization. It has been demonstrated that the surfaces of CNTs can be easily modified in numerous ways, either by covalent or non-covalent functionalization. All the facts mentioned before reveal that carbon nanotubes, and specially multiwalled carbon nanotubes, have great analytical potential as an effective solid-phase extraction adsorbent for chelates or ion pairs of metal ions, organic compounds, and organometallic compounds.

Based on these considerations, it could be summarized that MIPs-CNTs composites represent useful innovative materials for analytical determination of target analytes in complex matrices.

\section{Molecularly Imprinted Polymers (MIPs): highly selective materials}

Molecular imprinting is a very useful technique to incorporate specific substrate recognition sites into polymers (Puoci et al., 2010). In particular, by this polymer synthesis technique, the formation of macromolecular networks characterized by specific recognition sites for a desired target molecule, named template could be obtained (Byrne \& Salian, 2008). The specific binding properties of MIP must be attributed to specific interactions between the template and the functional groups in the polymeric network, thus the choice of the functional monomers is of primary importance to obtain performing imprinted materials (Puoci et al., 2007; Cirillo et al, 2010, 2011a)

In the synthesis of these macromolecular system, many parameters involved can affect the information associated with the binding sites, such as functional monomers/polymers, crosslinkers and solvents/porogens. Thus, both the feasibility of imprinting and the proper preparation conditions need exploration for the preparation of efficient imprinted materials (Liu Z. et al., 2010). It is important to state that MIP can be obtained in different formats, depending on the preparation method followed. To date, the most common polymerizations for preparing MIPs involve conventional solution, suspension, precipitation, multi-step swelling and emulsion core-shell. There are also other methods, such as aerosol or surface rearrangement of latex particles, but they are not used routinely (Puoci et al., 2011).

MIPs are stable polymers with molecular recognition abilities and resistant to a wide range of conditions ( $\mathrm{pH}$, organic solvents, temperature, pressure), and were used for several different applications, such as chromatographic stationary phases (Hishiya et al., 2003), enantiomeric separation (Adbo \& Nicholls, 2001), solid-phase extraction (SPE) (El-Sheikh et al., 2010), and catalysis (Anderson et al., 2005); they were also used as receptors (Haupt, 2003), antibodies (Svitel et al., 2001), enzyme mimics (Nicholls et al., 1996), affinity and sensing materials (Syu et al., 2006), and, in recent years, pharmaceutical applications, such as drug discovery, drug purification, or drug delivery (Mosbach, 2006; Yu Y. et al., 2002; Caldorera-Moore \& Peppas, 2009; Hilt \& Byrne, 2004). 
MIPs can be synthesized following three different imprinting approaches named covalent, non-covalent and semi-covalent procedure, according to the kind of interaction between a template and functional groups during the synthesis and recognition phases (Caro et al., 2002).

In the non-covalent procedure (Figure 1), non-covalent interactions (hydrogen bonding, $\mathrm{p}-\mathrm{p}$ interactions, Van der Waals forces, etc.) are involved in both the synthesis and the recognition step (Joshi et al., 1998). This method is still the most widely used method to prepare MIP because of the advantages that it offers from the point of view of synthesis. The covalent protocol requires the formation of covalent bonds between the template and the functional monomer prior to polymerization, as well as between template and functional group in the imprinted cavities during the re-binding process (Ikegami et al., 2004). Finally, the semi-covalent approach is a hybrid of the two previous methods. Specifically, covalent bonds are established between the template and the functional monomers before polymerization, while, once the template has been removed from the polymer matrix, the subsequent re-binding of the analyte to the MIP exploits non-covalent interactions (Curcio et al., 2010).

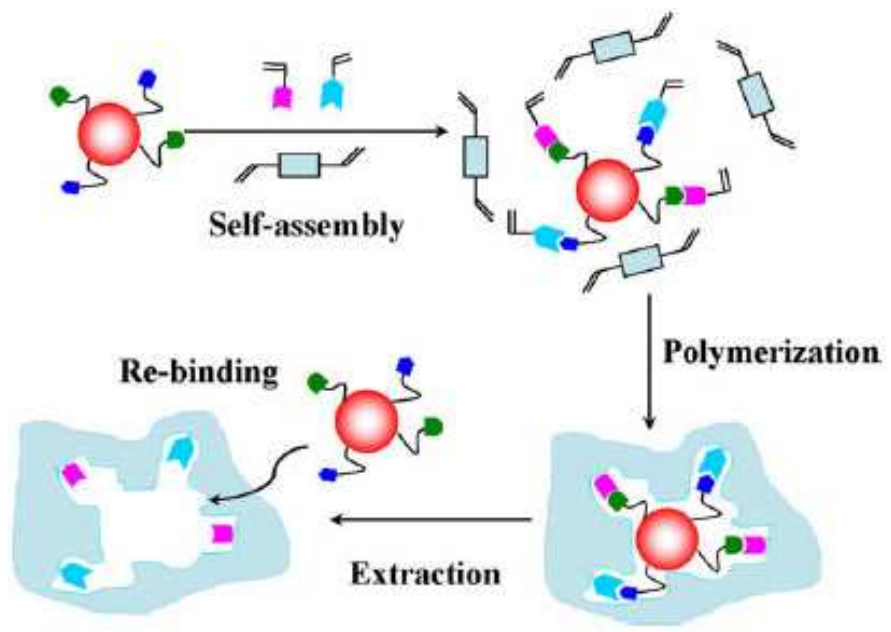

Fig. 1. Schematic representation of Non-Covalent Molecular Imprinting Process. Adapted from Liu Z. et al., 2010.

The binding sites obtained by molecular imprinting show different characteristics, depending on the type of imprinted approach. The average affinity of binding site prepared using bonding by non-covalent forces is generally weaker than those prepared using covalent methods because electrostatic, hydrogen bonding, $\Pi-\Pi$ and hydrophobic interactions, between the template and the functional monomers, are used exclusively in forming the molecular assemblies (Hwang \& Lee, 2002). However, when covalent bonds are established between the template and the functional monomer prior to polymerization, this gives rise to better defined and more homogeneous binding sites than the non-covalent approach, since the template-functional monomer interactions are far more stable and defined during the imprinting process. 
It should also be mentioned that, as a control in each polymerization, a non-imprinted polymer (NIP) is also synthesised in the same way as the MIP but in absence of the template. To evaluate the imprinting effect, the selectivities of the NIP and MIP are then compared.

\section{Carbon nanotubes: fascinating nano-objects}

In the last decade, the dramatic development of nanotechnology in material science and engineering has led to the study and the development of innovative nanostructured materials (Xu T. et al., 2007; Niemeyer, 2001; Cui \& Gao, 2003; Whitesides, 2003): certain materials with delicate structures of "small" sizes, falling in the 1-100 nm range, and specific properties and functions related to the "size effect" (Safarik \& Safarikova, 2002; Laval et al., 1999). In particular, extensive researches have been focused on medicine and biomedical engineering for the investigation of the interactions between nanomaterials and biological systems (Foldvari \& Bagonluri, 2008; Bianco et al., 2005; Desai, 2000). Potential products of bionanotechnology in the pharmaceutical and biomedical industry are refered as nanomedicines, including materials to be employed as clinical bio-analytical diagnostics (Bianco et al., 2005; Pantarotto et al., 2003), carriers to improve controlled and targeted drug release (Leary et al., 2006; Sinha \& Yeow, 2005) and additives to improve solubility and bioavailability of poorly soluble drugs (Ajayan et al., 1993), novel tissue engineered scaffolds and devices (Bauer et al., 2004; Mazzola, 2003; Kikuchi et al., 2004).

Within the realm of bionanotechnology, carbon nanotubes (CNTs), a major class of carbonbased tubular nanostructures have been denoted great interest in the scientific community (Ke \& Qiao, 2007; Klingeler \& Sim, 2011).

The walls of CNTs are made up of a hexagonal lattice of carbon atoms analogous to the atomic planes of graphite (Dresselhaus et al., 2004). CNTs can be imaginatively produced by rolling up a graphene sheet (a single layer of graphite) forming a single-walled CNTs (SWCNTs), or by rolling up many graphene layers to form concentric cylinders (multiwalled CNTs; MWCNTs). The ends of CNT may be closed with halfspheres of fullerens. MWNTs are comprised of two up to several to tens of concentric carbon cylinders and thus generally have a larger outer diameter $(2.5-100 \mathrm{~nm})$ than SWNTs $(0.6-2.4 \mathrm{~nm})$ (Joselevich, 2004) (Figure 2).

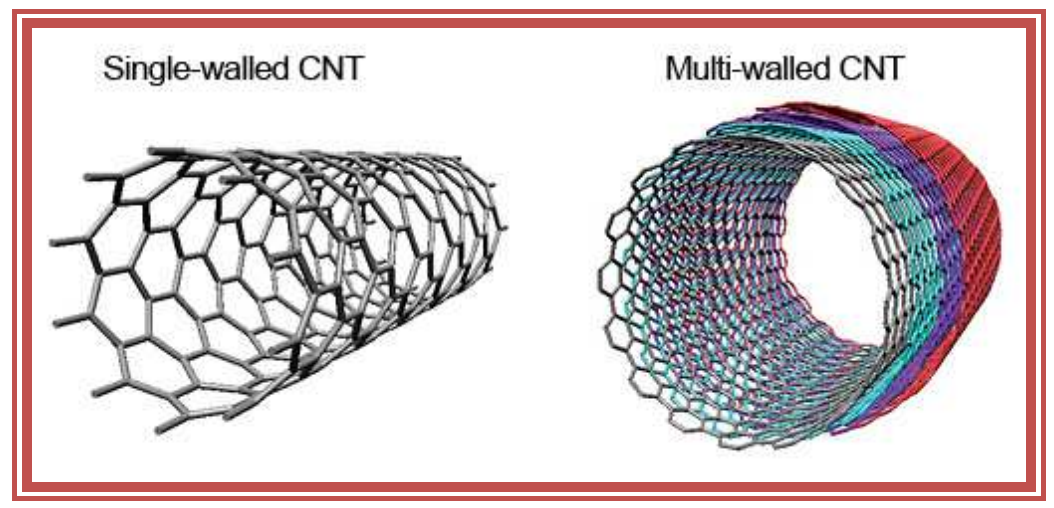

Fig. 2. Schematic representation of SWNTs and MWNTs. 
Although there have been many interesting and successful attempts to grow CNTs by various methods (Klingeler et al., 2008; Vyalikh et al., 2008), the three most widely used techniques are: arc discharge, laser ablation, and chemical vapor deposition (CVD) (Ando et al., 2004).

The arc-discharge method is the one by which CNTs were first produced and recognized. In a model system, a dc arc voltage is applied between two graphite rods in the presence of an appropriate ambient gas. This method is useful for the production of both CNTs and fullerenes. In particular, when pure graphite rods are used, fullerenes are deposited in the form of soot in the chamber (Saito et al., 1992). However, a small part of the evaporated anode is deposited on the cathode, which includes CNTs (Iijima, 1991). As described by Ando et al., 2004, these CNTs represent MWNTs. They are found not only on the top surface of the cathode deposit (Ando, 1993) but also deep inside the deposit (Ando \& Iijima, 1993). Large-scale synthesis of MWNTs by arc discharge has been achieved (Ebbesen \& Ajayan, 1992; Colbert et al., 1994) in He gas. The same methodology could be applied to the synthesis of SWNTs if a graphite rod containing metal catalysts ( $\mathrm{Fe}, \mathrm{Co}$, etc.) is used as the anode with a pure graphite cathode (Iijima \& Ichihashi, 1993; Bethune et al., 1993). By using a dc pulsed arc discharge inside a furnace, homogeneous conditions in arc discharge are achieved and high-quality DWNTs are synthesized by a method called high-temperature pulsed arc discharge (Sugai et al., 1999, 2000, 2003; Shimada et al., 2004).

The laser ablation, based on the high energy density of lasers (typically a YAG or $\mathrm{CO}_{2}$ laser) which is suitable for materials with a high boiling temperature such as carbon, was developed for fullerene and CNT production by Smalley's group (Guo T. et al., 1992; Thess et al., 1996). The laser has sufficiently high energy density not to cleave the target into graphite particles but to vaporize it at the molecular level converting the graphite vapor into amorphous carbon as the starting material of SWNTs (Puretzky et al., 2000; Sen et al., 2000; Kokai et al., 2000). The annealing conditions of the amorphous carbon in the laser ablation method are more homogeneous than those of the arc-discharge method, in which the electrodes and the convection flow disturb the homogeneity of the temperature and flow rate (Zhao X. et al., 2003; Kanai et al., 2001).

Chemical Vapor Deposition (CVD) is a simple and economic technique for synthesizing CNTs at low temperature and ambient pressure. Usually, a carbon feedstock is thermally decomposed in the presence of a metal catalyst (Cirillo et al., 2011b). The generated carbon dissolves in the catalyst particles and, after saturation, is deposited in the shape of CNTs.

To be distinguished from the many kinds of CVD used for various purposes, the method is also known as thermal or catalytic. Compared with arc-discharge and laser methods, CVD is more versatile because it offers better control over growth parameters. Furthermore, it harnesses a variety of hydrocarbons in any state (solid, liquid, or gas), enables the use of various substrates, and allows CNTs growth in a variety of forms, such as powder, thin or thick films, aligned or entangled, straight or coiled, or even a desired architecture of nanotubes at predefined sites on a patterned substrate. MWNTs were grown from benzene, ethylene, methane, and many other hydrocarbons (Endo et al., 1993; José-Yacamán et al., 1993; Satiskumar et al., 1999; Hernadi et al., 1996). SWNTs were first produced by Dai et al. from disproportionation of CO, and SWNTs were also produced from benzene, acetylene, ethylene, and methane using various catalysts. (Cheng et al., 1998; Satishkumar et al., 1998; Hafner et al., 1998; Kong J. et al., 1998; Flahaut et al., 1999). Due to lower synthesis 
temperatures CVD grown CNTs exhibit a lower crystallinity than tubes produced using the two alternative methods mentioned above.

When considering the whole of CNTs applications, the solubilization of pristine CNTs in aqueous solvents remains an obstacle to realizing their potential, due to the rather hydrophobic character of the graphene sidewalls. To successfully disperse CNTs the dispersing medium should be capable of both wetting the hydrophobic tube surfaces and modifying the tube surfaces to decrease tube aggregation. Four basic approaches have been used to obtain a dispersion: surfactant-assisted dispersion (Ham et al., 2005; Islam et al., 2003; Moore et al., 2003; Yurekli et al., 2004; Vaisman et al., 2006), solvent dispersion (Fu \& Sun, 2003; Ausman et al., 2000; Kim D.S. et al., 2005), functionalization of CNT sidewalls (Dyke \& Tour 2004; Fernando et al., 2004; Peng et al., 2003), and biomolecular dispersion (Gigliotti et al., 2006).

\section{Chemical sensing}

Before exploring the use of CNTs in chemical and electrochemical sensing it should be pointed out that the term sensor refers to a device that responds to a physical or chemical stimulus by producing a signal, usually an electrical one (Hillberg et al., 2005), while a biosensor is a sensor that uses biological selectivity to limit perception to the specific molecule of interest. A typical biosensor consists of two main components: the chemosensory materials (receptors) that can selectively bind target analytes and the efficient transducer that can transform the binding events into a readable signal output related to the analyte concentration in the sample (Eggins, 2002). The efficiency of chemosensors is largely dependent on the selectivity and sensitivity of the used sensory materials to a target species. In the traditional approaches a biological or biologically derived sensing element acting as a receptor is immobilized on the surface of a physical transducer to provide selective binding of analytes (Orellana \& Moreno-Bondi, 2005; Jiang \& Ju, 2007). As a sensing element, it is possible to use either biological macromolecules (e.g. antibodies, enzymes, receptors and ion channel proteins, nucleic acids, aptamers and peptide nucleic acids) or biological systems (e.g. ex vivo tissue, microorganisms, isolated whole cells and organelles). However, the small surface area and non-tunable surface properties of transducers greatly limit the efficiency of chemosensors, especially for the detection of ultratrace analytes. Recently, nanomaterials have found a wide range of applications as a material foundation of chemosensors, and have exhibited various degrees of success in the improvement of detection sensitivity and selectivity (Gao D. et al., 2007; Xie et al., 2006; Banholzer et al., 2008) due to their unique electrical, optical, catalytic or magnetic properties (Chen J.R. et al., 2004) and large surface-to-volume ratio (Xie et al., 2008).

\subsection{CNTs in chemical sensing}

Among nanomaterials, carbon surfaces represent very attractive materials for electrochemical studies, such as biosensor applications, due to their different allotropes (graphite, diamond and fullerenes/nanotubes). Carbon electrodes are well polarizable. However, their electrical conductivity strongly depends on the thermal treatment, microtexture, hybridization and content of heteroatoms. Additionally, the amphoteric character of carbon allows use of the rich electrochemical properties of this element from donor to acceptor state. Application of recently developed carbon materials include, 
environment-friendly and energy-saving automotive parts, high-purity components in semiconductor manufacturing equipment for highly integrated chips, internal walls of vacuum vessels in the nuclear fusion reactors expected to be an energy source in the 21st century, and negative electrodes of lithium ion secondary batteries, of which demand is rapidly increasing with the popularization of mobile electronic instruments (Kazua, 1999). During the last years a great interest has been focused on the application of carbons (Flavel et al., 2009; Ma G.P. et al., 2009) as electrode materials because of their accessibility, easy processability and relatively low cost. They are chemically stable in different solutions (from strongly acidic to basic) and able to show performance in a wide range of temperatures. Already well-established chemical and physical methods of activation allow for the production of materials with a developed surface area and a controlled distribution of pores that determine the electrode/electrolyte interface for electrochemical applications.

The possibility of using the activated carbon without binding substances (e.g. fibrous fabrics or felts) gives an additional advantage from the construction point of view. Unique properties of ultra-microelectrodes (UMEs) make them very attractive in electroanalytical measurements which require high spatial and temporal resolution (Wigthman, 1988). At ultra-microelectrodes, at typical slow scan rates of voltammetry, signal to noise ratios $(\mathrm{S} / \mathrm{N})$ can increase up to one decade due to efficient mass transportation to the electrode resulting from edge effects. In addition, because of the small dimensions and low IR drop, fast scan voltammetric measurements (Garreau et al., 1990; Hsueh et al., 1993) and measurements in highly resistive media are possible at UMEs (Howell \& Wightman, 1984) while high spatial resolution and minimal tissue damage (Musallam et al., 2007). can be achieved in vivo analysis. Microelectrodes are useful for measurements for changes in easily oxidized neurotransmitter concentrations in extracellular brain fluid (Kawagoe et al., 1993) as they provide a way to observe the rapid chemical changes associated with the release of neurotransmitters from neurons and their subsequent removal from the extracellular fluid (Atesa \& Sarac, 2009).

The nanodimensions of CNTs guarantee a very large active surface area and are especially suited for the conception of miniaturized sensors. In addition to the high porosity and reactivity, this makes them ideal candidates for the storage of neutral species as well as electron donors, when used as electrodes in electrochemical reactions, for which they may also be called "nanoelectrodes" (Basabe-Desmonts et al., 2007; Daniel et al., 2007; Guo et al., 2004). Hence, it is not surprising that gas sensors made from individual nanotubes show good sensitivities at room temperature (J. Kong et al., 2001; Vasanth Kumar et al., 2010, 2011) in comparison to commercially available classical semiconductor sensors, which in general operate above $200^{\circ} \mathrm{C}$. However, a necessary prerequisite is that the molecules to be detected must have a distinct electron donating or accepting ability, which is fulfilled, for example, by ammonia $\left(\mathrm{NH}_{3}\right)$ as a donor and nitrogen dioxide $\left(\mathrm{NO}_{2}\right)$ as an acceptor. The adsorption of these molecules on the nanotubes is associated with a partial charge transfer, which alters the charge-carrier concentration or, alternatively, the adsorbed molecules may affect the potential barriers present at the tube-electrode contacts. In any event, the resulting change in the electrical resistance of the nanotube is utilized as a sensor signal. However, for the detection of molecules that are only weakly adsorbed (e.g., carbon monoxide and hydrogen), the change in resistance is often too small. A possible method to overcome this drawback is accomplished by the modification of the nanotube sidewalls with nanoparticles made of a suitable metal. For instance, sensitive hydrogen sensors operating at room 
temperature can be obtained via the deposition of palladium nanoparticles either by direct evaporation (Kong J. et al., 2000) or through electrodeposition (Geng et al., 2004; Teles et al., 2008). Electrodeposition offers the specific advantage of site-selectivity, since the metal decoration is restricted to the current-carrying tubes, so that the remaining substrate surface is unaffected. An example is a semiconducting SWCNT with electrodeposited Pd particles upon exposure to hydrogen. The operation mechanism is largely analogous to that of a palladium gate field-effect transistor realized within classical silicon technology (Lundstroem et al., 1975). Specifically, molecular hydrogen is split on the surface of a Pd particle into atomic hydrogen, which diffuses to the Pd/SWCNT interface. At this interface, a dipole layer is formed, which acts like a microscopic gate electrode that locally changes the charge-carrier concentration. It should be mentioned that the recovery of this type of roomtemperature-operated hydrogen sensor requires a supply of oxygen to remove the hydrogen atoms in the form of water (Balasubramanian \& Burghard, 2005). Carbon nanotubes exhibit high electron transfer rates for different redox couples in various media (Balasubramanian et al., 2004) which has stimulated an increasing amount of research into CNT based amperometric sensors for the detection of specific analytes in solution. The length scales of CNTs are similar to that of typical biological molecules, which gives CNTs an edge over other materials in functioning as effective electrodes in bioelectrochemical sensing (Guiseppi-Elie et al., 2002). In particular, their high aspect ratio and their diameter in the nanometer range make CNTs particularly well suited for direct electrochemical communication with the redox site of a protein, without requiring any mediator. When properly arranged, a nano- tube should have the capability to act as a $1 \mathrm{D}$ channel that guides electrons towards the redox center. These materials can be used to preconcentrate analytes and for the magnetic separation and molecular identification of biomolecules, and organic and inorganic species (AguilarArteaga et al., 2010).

The application of CNTs as absorption and/or transducing materials was shown in several different works. Recently, a critical review dealing with the adsorption mechanism of analytes of different nature on carbon nanotubes was published (Cruz et al., 2010; Fontanals et al., 2007; See et al., 2010; Petrovic et al., 2010; Zeng J. et al., 2009; Augusto et al., 2010; Lucena et al., 2011;). The authors stated that this procedure cannot be explained by a single mechanism but through a combination of mechanisms. Indeed, the introduction of functional groups on the surface can facilitate the selective interaction with a given family of compounds. However, this fact has not yet been exploited for the analysis of urine samples. MWCNTs are proposed as a sorbent in an off-line SPE method for the determination of antidepressants using LC and UV detection (Bakker \& Qin, 2006). MWCNTs have been applied as adsorbents for preconcentration of sulfonylurea herbicides (Lemos et al., 2008; Zhou Q. et al., 2006a, 2007), bisphenol A, 4-n-nonylphenol, 4-tert-octylphenol (Cai et al., 2003a), dichlorodiphenyltrichloroethane and its metabolites (Zhou Q. et al., 2006b); atrazine, simazine (Zhou Q. et al., 2006c), and trihalomethanes (Lu et al., 2005) in environmental water samples, barbiturates determination in pork (Zhao H. et al., 2007), for simultaneous determination of 10 sulfonamides in eggs and pork (Fang et al., 2006), for trapping volatile organic compounds in a purge-and trap GC system (Li Q. et al., 2004), to extract diethylphthalate, di-n-propyl-phthalate, di-iso-butyl-phthalate, and di-cyclohexylphthalate from aqueous solutions (Cai et al., 2003b).

Direct electron transfer has been achieved with various types of CNT electrodes for cytochrome c (Wang J. et al., 2002), horseradish peroxidase (Zhao Y. et al., 2002), myoglobin 
(Zhao G.C. et al., 2003), as well as glucose oxidase (Guiseppi-Elie et al., 2003). It is noteworthy that in the latter case, the redox-active center is deeply embedded within the protein. In some cases, an oxidative pretreatment that introduces negatively charged surface groups on the CNTs was necessary to achieve high electron transfer rates. In a strategy to optimize the accessibility of the redox center, aligned CNT arrays have been fabricated using self-assembly techniques, followed by the covalent attachment of microperoxidase to the tube ends (Gooding et al., 2003). On this basis, various types of amperometric biosensors have been fabricated (Rubianes et al., 2003; Wang J. \& Musameh, 2003; Wang J. et al., 2003). A glucose sensor, for example, is obtained by immobilizing glucose oxidase onto SWCNTs deposited on a glassy carbon surface (Davis et al., 2003). Hrapovic et al., 2004 combined platinum nanoparticles with carbon nanotubes and developed a new approach for the electrochemical detection of glucose (Aponte et al., 2006). Effective deposition of $\mathrm{Pt}$ nanoparticles on SWCNT was achieved by using a negatively charged polymer, Nafion, to dissolve and disperse SWCNT. Pt nanoparticles can easily be deposited on the Nafionmodified CNT due to charge interactions. Compared to the sensors containing only $\mathrm{Pt}$ or $\mathrm{CNT}$, the integration of $\mathrm{Pt}$ and CNT lead to improved sensitivity and detection limit.

Zhang and Gorski used carbon nanotubes and redox mediators dispersed into a polymeric matrix for NADH detection and found a reduction of the overpotential (by $0.3 \mathrm{~V}$ ), a higher sensitivity, and faster response times (Zhang M. \& Gorski, 2005). Wang J. \& Musameh, 2004 reported on the use of carbon nanotubemodified glassy carbon electrodes in order to accelerate the electrooxidation of insulin, which resulted in a lowering of the required detection potential and a $14 \mathrm{nM}$ detection limit as studied by flow injection analysis. Wang K. et al., 2005 proposed a potentiometric sensor for ascorbic acid on the basis of cobalt phthalocyanine nanoparticles directly coated on a glassy carbon electrode by drop coating. The authors explained the selective and rapid response to ascorbic acid on the basis of the redox potential, with cobalt acting as the mediator.

Kerman et al., 2004 also described the label-free electrochemical detection of DNA based on the direct attachment of adenine probes to the sidewall and end of functionalized MWCNTs. The MWCNTs were attached onto the carbon paste electrode surface modified with thymine probes by hybridization between adenine and thymine. The combination of sidewall and end functionalization of MWNT showed enhancement of the guanine oxidation signal in the direct measurement compared to the ones from only end-modified MWCNT.

The attachment of numerous enzymes on a single carbon nanotube label provided for enormous signal enhancement. Wang J. et al., 2004 reported on a novel method to dramatically amplify enzyme-based DNA sensing by using carbon nanotubes. In the new sensing scheme, the DNA duplex acted as connectors between microbeads and CNTs. The CNT loaded with enzymes linked to the magnetic microbeads through the interaction of complementary oligonucleotides. Without the recognition event, the CNT cannot attach to the particles and is removed during the magnetic separation. The CNTs function as carriers for enzyme tags, and the enzyme reaction products were also accumulated in the CNTs. The coupling of enzyme-tagged CNTs provided a better detection limit than single-enzyme labels and a conventional glassy carbon transducer.

\subsection{MIPs in chemical sensing}

In the sensors and biosensors technology, often there is the overriding complication that it is unusual, in "real" samples, for there to be a single species present. More commonly an 
analyte of interest is accompanied by a number of different species, all present at different concentrations and all adding to the complexity of the analytical problem.

All over the world, billions of dollars are spent annually on chemical/biological detections related to medical diagnosis, environmental monitoring, public security and food safety because lab analysis using expensive equipment is usually cumbersome and timeconsuming. Therefore, there has been a pressing societal need for the development of chemo/biosensors for the detection of various analytes in solution and atmosphere, which are both less expensive and simpler to construct and operate. Although considerable progress was made in the past several decades, the chemo/biosensor field remains underdeveloped and at a low level of commercialization because of the lack of alternative strategies and multidisciplinary approaches (Guan et al., 2008).

The standard approach to the analytical analysis of complex matrices is the separation of the different components. Typically, therefore, before a sensor can be used to perceive and quantify one component in a mixed solution, the various components of the complex mixture must be separated, usually by a chromatographic process, so that some form of non-selective sensor, e.g. UV absorbance measurements, can be used to detect and quantify each individual component. In order to improve the performance of chemical sensors, an improvement of their selectivity is required, so that a particular chemical species can be detected and assayed without the need for a possibly lengthy separation stage. In this direction, a technological approach is the development of the biosensor (Updike \& Hicks, 1967).

Molecular imprinting is one of the most efficient strategies that offer a synthetic route to artificial recognition systems by a template polymerization technique (Ye \& Mosbach, 2001; Spivak, 2005; Zhang H.Q. et al., 2006). While most research in this direction is targeted to the design of chromatographic stationary phases, their use in electrochemical sensors is expanding for electroactive analytes. In convincing work, the group of Mandler explored sol-gel polymers imprinted with the organophosphate pesticide parathion and performed gasphase and liquid-phase partitioning experiments as well as cyclic voltammetric studies (Marx et al., 2004). Imprinted films showed a more than 10-fold increased equilibrium binding over nonimprinted polymers and discriminated well against a range of other structurally similar organophosphates.

To date molecularly imprinted polymers have been successfully used with most types of transduction platforms and a range of methods have been used to bring about close integration of the platform with the polymer (Adhikari \& Majumdar 2004). By using MIP it is possible to overcome the commonly founded limitations in the traditional biosensor approach (Orellana \& Moreno-Bondi, 2005; Jiang \& Ju, 2007), based on the use of biological macromolecules (e.g. antibodies, enzymes, receptors and ion channel proteins, nucleic acids, aptamers and peptide nucleic acids) or biological systems (e.g. ex vivo tissue, microorganisms, isolated whole cells and organelles) as sensing element. In the last years, indeed, although biological receptors have specific molecular affinity and have been widely used in diagnostic bioassays and chemo/biosensors, great affords have been made in synthesizing artificial recognition receptors to overcome the limit in the efficiency of chemosensors, especially for the detection of ultratrace analytes due to the small surface area and non-tunable surface properties of transducers. Another limitation of traditional biosensors is that often natural receptors for many detected analytes do not exist; 
furthermore, they are produced via complex protocols with a high cost and require specific handling conditions because of their poor stability (Whitcombe et al., 2000; Wulff, 2002; Haupt \& Mosbach, 2000; Ye \& Haupt, 2004).

During the past ten years, the literatures on the development of MIP-based sensors, in particularly electrochemical (Riskin et al., 2008;) and optical (McDonagh et al., 2008; BasabeDesmonts et al., 2007; Li J. et al., 2007a; Feng et al., 2008) sensors, have been dramatically growing (Nilsson et al., 2007; Ramanavicius et al., 2006). It was found that the manufacture of composites consisting of molecularly imprinted conducting polymers results in obtaining materials that exhibit both predetermined selective molecular recognition and electrical conductivity (Deore et al, 2000). This type of materials, mostly frequented based on overoxidized polypyrrole, is of special interest for use in the field of sensor technology (Shiigi et al., 2003).

MIP-based electrochemical sensors were first reported in the early 1990s by Mosbach's group (Andersson et al., 1990), and to date, remarkable progress in MIP-based electrochemical sensors have been achieved in the use and the performance of conductometric/potentiometric MIP nanomaterials (Zhou Y.X. et al., 2003), which were used to detect many different analytes (Augisto et al., 2010) such as barbituric acid (Mirsky et al., 1999), amino acid derivatives (Panasyuk et al., 1999), morphine (Kriz et al., 1995), atrazine (Kim Y. et al., 2007), benzyltriphenylphosphonium chloride (Kriz \& Mosbach, 1995), thiophenol (Kröger et al., 1999), glutamic acid (Ouyang et al., 2007), folic acid (Prasad et al., 2010a; Prasad et al., 2010c), tolazoline (Zhang Z. et al., 2010a), tryptophan (Prasad et al., 2010d; Kong Y. et al., 2010), clindamycin (Zhang J. et al., 2010), 2,4-dichlorophenoxy acetic acid (Xie et al, 2010), histamine (Bongaers et al., 2010), caffeine (Alizadeh et al., 2010; Vinjamuri et al., 2008), theophylline (Kan et al., 2010) uracil and 5-fluorouracil (Prasad et al., 2009), salicylic acid (Kang et al., 2009), uric acid (Patel et al., 2009), resveratrol (Xiang \& Li, 2009), hydroquinone (Kan et al., 2009; Kan et al., 2008a), bisphenol (Kolarz \& Jakubiak, 2008), and dopamine (Kan et al., 2008b).

Despite the application of MIPs as sensor matrices or separation materials, they suffer from basic limitations associated with the limited concentration of imprinted sites, and the bulk volume of the polymer matrices that requires long diffusion paths of the imprinted host molecules. These limitations lead to inefficient sensing or separation processes (Shi et al., 2007). In order to increase the efficiency of MISPE, a method is increasing the surface area of polymer. Higher surface area can contain more functional groups, thus the interaction between polymer and bioactive compounds will be increased accordingly (Tian et al., 2011). A useful approach is the fabrication of robust multilayer structures by the photocrosslinking of the layers (Sun et al., 1998, 2000). This process transformed the electrostatic interlayer stabilizing interactions into covalent bonds. This achievement, together with the stated limitations of MIPs, suggested that the surface imprinting of LbL nanostructured films might be a viable technique to fabricate effective MIP matrices.

\section{CNTs-MIPs composites: innovative materials for analytical determinations}

Among the different applications of CNTs in nanotechnology, polymer composites, consisting of additives and polymer matrices, including thermoplastics, thermosets and elastomers, are considered to be an important group of relatively inexpensive materials for many engineering applications (Ma et al., 2010; Yang et al., 2007). The technology implications are significant to 
many fields, from semiconductor device manufacturing to emerging areas of nanobiotechnology, nanofluidics, and chemistry where the ability to mold structures with molecular dimensions might open up new pathways to molecular recognition, drug discovery, catalysis, and molecule specific chemio-biosensing (Hua et al., 2004).

The main approaches for the fabrication of these materials can be divided into "grafting to" and "grafting from" approaches (Liu M. et al., 2009; Baskaran et al., 2004).

The "grafting to" approach involves pre-formed polymer chains reacting with the surface of either pristine or pre-functionalized carbon nanotubes. (See Figure 3). The main approaches exploited in this functionalization strategy are radical or carbanion additions as well as cycloaddition reactions to the CNT double bonds. Since the curvature of the carbon nanostructures imparts a significant strain upon the $\mathrm{sp}^{2}$ hybridized carbon atoms that make up their framework, the energy barrier required to convert these atoms to $\mathrm{sp}^{3}$ hybridization is lower than that of the flat graphene sheets, making them susceptible to various addition reactions. Therefore, to exploit this chemistry, it is only necessary to produce a polymer centered transient in the presence of CNT material. Alternatively, defect sites on the surface of oxidized CNTs, as openended nanostructures with terminal carboxylic acid groups, allow covalent linkages of oligomer or polymer chains. The "grafting to" method onto CNT defect sites means that the readymade polymers with reactive end groups can react with the functional groups on the nanotube surfaces. An advantage of the "grafting to" method is that preformed commercial polymers of controlled molecular weight and polydispersity can be used. The main limitation of the technique is that initial binding of polymer chains sterically hinders diffusion of additional macromolecules to the CNT surface, leading to a low grafting density. Also, only polymers containing reactive functional groups can be used.

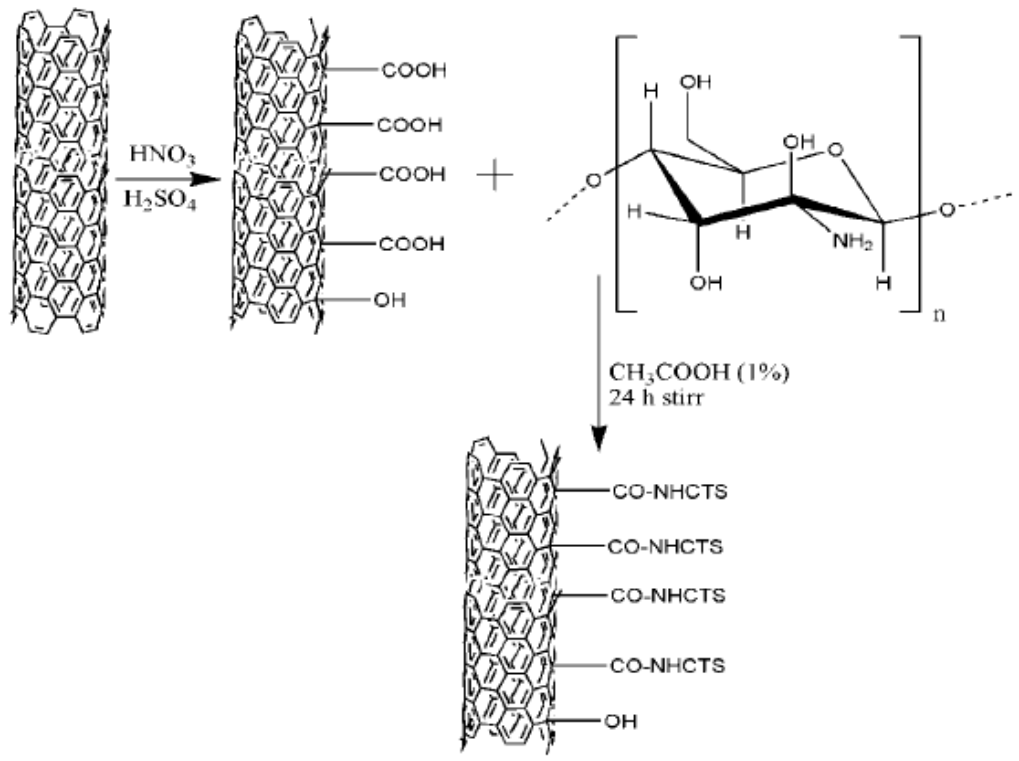

Fig. 3. Synthesis of CNTs-polymer composites by "Grafting to" approach as reported by Venkatesan \& Kim, 2010. 
The "grafting from" approach involves the polymerization of monomers from surfacederived initiators on CNTs. These initiators are covalently attached using the various functionalization reactions developed for small molecules, including acid-defect group chemistry and side-wall functionalization of CNTs. (See Figure 4). The advantage of "grafting from" approach is that the polymer growth is not limited by steric hindrance, allowing high molecular weight polymers to be efficiently grafted. In addition, nanotubepolymer composites with quite high grafting density can be prepared. However, this method requires strict control of the amounts of initiator and substrate as well as accurate control of conditions required for the polymerization reaction. Moreover, the continuous $\Pi-$ electronic properties of CNTs would be destructed by the acid oxidation, even worse, CNTs may be destroyed to several hundred nanometers in length. As a result, compared with the "grafting from", the "grafting to" has much less alteration of the structure of CNTs (Yan \& Yang, 2009; Mylvaganam \& Zhang, 2004; Zhang M.N. et al., 2004).
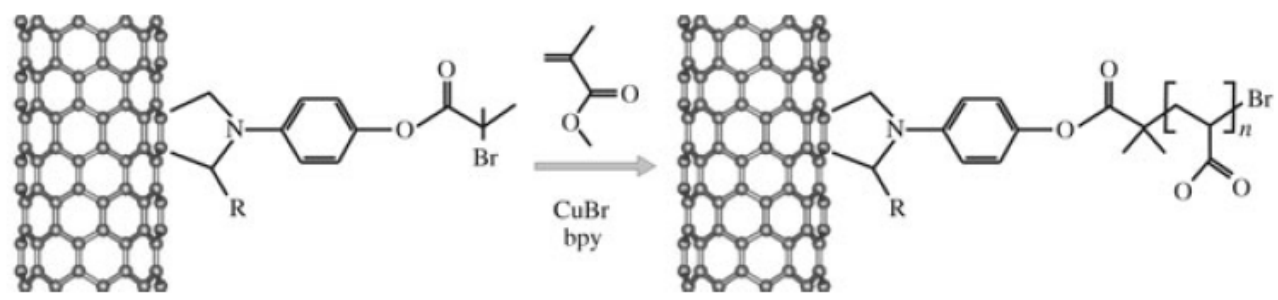

Fig. 4. Synthesis of CNTs-polymer composites by "Grafting from" approach as reported by Balasubramanian \& Burghard, 2005.

Many techniques including esterification (Gao C. et al., 2007; Sano et al., 2001; Kahn et al., 2002; Huang W. et al., 2003; Lin et al., 2003), "click" chemistry (Li H.M. et al., 2005), layer-bylayer self-assembly (Kong H. et al., 2005; He \& Bayachou, 2005; Qin et al., 2005; Artyukhin et al., 2004), pyrene moiety adsorption (Bahun et al., 2006; Martin et al., 2004; Qu et al., 2002; Petrov et al., 2003; Gomez et al., 2003), radical coupling (Liu Y.Q. et al., 2005; Lou et al., 2004), anionic coupling (Huang H.M. et al.,2004), radical polymerization (Qin et al., 2004a; Shaffer \& Koziol, 2002), supercritical $\mathrm{CO}_{2}$-solubilized polymerization or coating (Wang J.W. et al., 2006; Dai et al., 2004), $\gamma$-ray irradiation (Xu H.X. et al., 2006), cathodic electrochemical grafting (Petrov et al., 2004) polycondensation (Zeng H.L. et al., 2006a; Gao C. et al., 2005; Nogales et al., 2004), reversible addition fragmentation chain-transfer (RAFT) polymerization (Xu G.Y. et al., 2006; You et al., 2006; Cui H. et al., 2004; Hong et al., 2005, 2006), anionic polymerization (Chen S.M. et al. 2006; Liu I.C. et al., 2004), ring-opening polymerization (Zeng H.L. et al., 2006b; Qu et al., 2005; Buffa et al., 2005; Gao J.B. et al., 2005) and atom transfer radical polymerization (ATRP) (Kong H. et al., 2004; Qin et al., 2004b; Yao et al., 2003) have been employed to functionalize CNTs with polymers.

CNTs exhibit a high aspect ratio and high conductivity, which makes CNTs excellent candidates for conducting composites (Sahoo et al., 2010) (Figure 5).

The observation of an enhancement of electrical conductivity by several orders of magnitude of CNTs in polymer matrices without compromising other performance aspects of the polymers such as their low weight, optical clarity, low melt viscosities, etc., has 

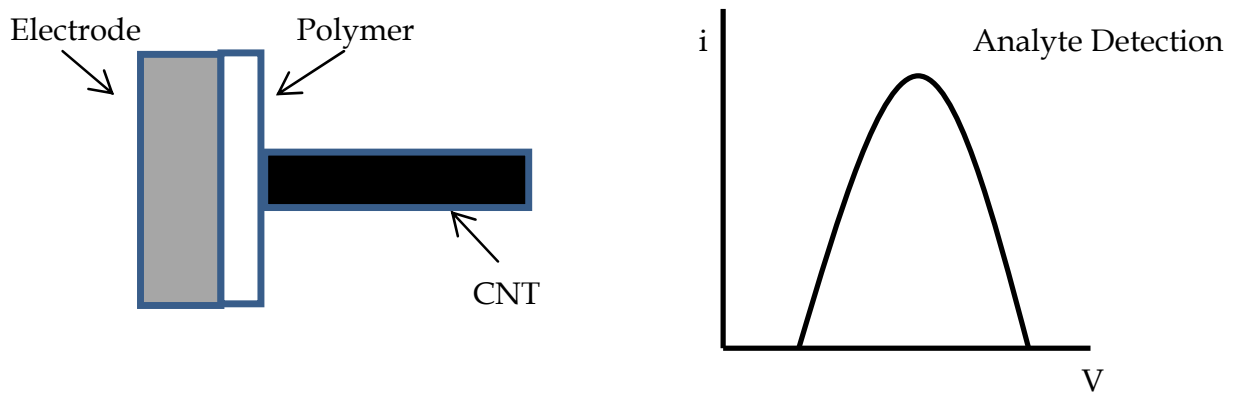

Fig. 5. Schematic representation of electrochemical detection by CNTs composite electrode. Adpted from Teles \& Fonseca, 2008.

triggered an enormous activity worldwide in this scientific area (Spitalsky et al., 2010). Nanotube-filled polymers could potentially, among the others, be used for transparent conductive coatings, electrostatic dissipation, electrostatic painting and electromagnetic interference shielding applications (Bauhofer \& Kovacs, 2009; Breuer \& Sundararaj, 2004; Moniruzzaman \& Winey, 2006; Winey et al., 2007). The electrical conductivity in CNTspolymer nanocomposites depends on dispersion (Sandler et al., 2003; Li J. et al., 2007b; Song \& Youn, 2005), alignment (Choi et al., 2003; Fangming et al., 2003), aspect ratio (Bai \& Allaoui, 2003; Bryning et al., 2005), degree of surface modification (Georgakilas et al., 2002) of CNTs, polymer types (Ramasubramaniam et al., 2003) and composite processing methods (Li J. et al., 2007b). Based on their characteristic, CNTs-polymer composites can behave as conductors, semiconductors or insulators (Maruccio et al., 2004).

CNTs-polymer composites were successfully synthesized and employed for different applications, both in biomedical and engineering fields. One of the most representative example is a study regarding an ammonia gas sensors based on single-walled carbon nanotubes functionalized with covalently attached poly(m-aminobenzenesulfonic acid). The sensor was operated as a chemiresistor, with the carbon nanotubes forming a random network between interdigitated electrodes, and improved response and recovery times were observed (on the order of $15 \mathrm{~min}$ ) (Bekyarova et al., 2004). In another work, a carbon nanotube/poly(ethylene-co-vinyl acetate) composite electrode was developed for amperometric detection in Capillary Electrophoresis (Frost et al., 2010). The new electrode also generated improved S/N, decreased fouling, and resulted in better long-term stability (Chen Z. et al., 2009). Zhou D. et al., 2008 describes a novel sieving matrix composed of both a quasi-interpenetrating polymer network (IPN) and PDMA functionalized MWNTs. Atom transfer radical polymerization was used to graft PDMA on MWNTs. The functionalized MWNTs were compatible with the quasi-IPN network. The rigid structure of MWNTs increased the stability and sieving ability of the matrix. Results showed that this novel matrix was advantageous in terms of resolution, speed, and reproducibility. Carbon nanotubes have been used to improve the efficiency of $\mathrm{Ru}(\mathrm{bpy}) 3^{2+}$ modified polyacrylamide electrode because of their high conductivity (Xing \& Yin, 2009). Carbon nanotubes modified with polypyrrole-silica nanocomposites seem very promising for electrochemical DNA sensor design (Ramanacius et al., 2006). MWCNTs were also grafted with poly(acrylamide) (PAAM) and with poly(N,Ndimethylacrylamide) (PDMA) at same grafting percentage by using $\mathrm{N}_{2}$ plasma technique and used in the removal of $\mathrm{Pb}^{2+}$ from aqueous solution under 
ambient conditions (Shao et al., 2010). Authors found that the grafted PAAM and PDMA improved MWCNT adsorption capacity in the removal of $\mathrm{Pb}^{2+}$ from large volumes of aqueous solutions. Furthermore, MWCNTgPAAM had much higher adsorption capacity than MWCNT-g-PDMA, which was attributed to higher amide group content in acrylamide than that in N,N-dimethylacrylamide.

A particular kind of CNTs-polymer composites is represented by CNTs-MIPs composites, in which the polymer part is a molecularly imprinted polymer (Chang et al., 2011; Walcarius et al., 2005). CNTs impart electrical conductivity to MIPs, while molecular imprinting on these one-dimensional nanostructures will endow the nanotubes with molecular recognition functions, further expanding their application fields (Guan et al., 2008). Several example of using these materials are reported in literature for biomedical, pharmaceutical and environmental applications (Figure 6).

In pharmaceutical fields, in Zhang Z. et al., 2010b, a novel sensitive and selective imprinted electrochemical sensor was constructed for the direct detection of L-histidine by combination of a molecular imprinting film and MWNTs. The sensor was fabricated onto an indium tin oxide electrode via stepwise modification of MWNTs and a thin film of MIPs via sol-gel technology. The introduced MWNTs exhibited noticeable enhancement on the sensitivity of the MIPs sensor, meanwhile, the molecularly imprinted film displayed high sensitivity and excellent selectivity for the target molecule. H. Y. Lee \& Kim, 2009 reports of the synthesis of CNTs-MIP composite to be potentially applied to probe materials in biosensor system for theophylline recognition based on CNT field effect. Hydroxyl-

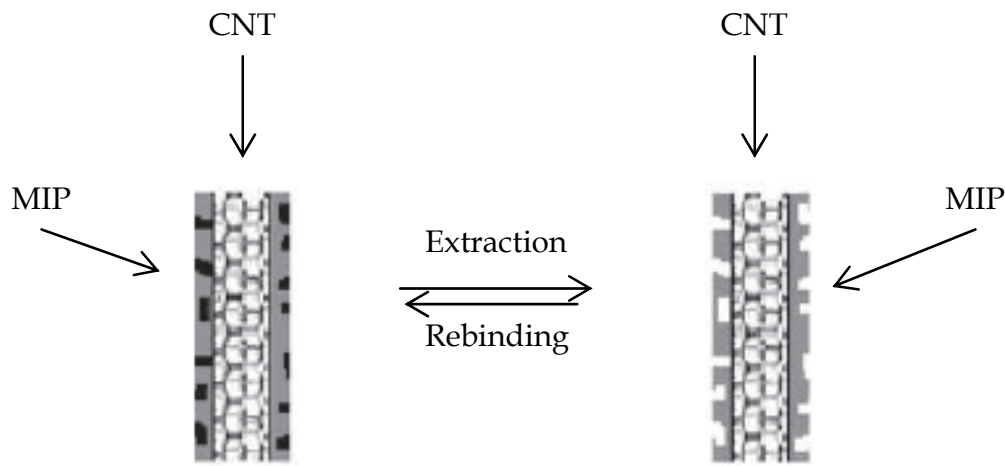

Fig. 6. Schematic representation of CNTs-MIPs recognition process. Adapted from Z. Zhang et al., 2010d.

functionalized CNT was modified by silanisation with 3-chloropropyl trimethoxysilane. The iniferter groups were then introduced by reacting the CNT-bound chloropropyl groups with sodium $\mathrm{N}, \mathrm{N}$-diethyldithiocarbamate. UV light-initiated copolymerization of ethylene glycol dimethacrylate (crosslinking agent) and methacrylic acid (functional monomer) resulted in grafting of MIP on CNT for theophylline as a model template. The theophylline-imprinted polymer on CNT showed higher binding capacity for theophylline than non-imprinted polymer on CNT and selectivity for theophylline over caffeine and theobromine (similar structure molecules). Another theophylline sensor 
based on CNTs-MIPs composites is shown in Lee E. et al., 2008. In this study acrylated Tween 20 was used as a linking molecule of MIPs to CNT. MIPs were formed for theophylline as a model template on the surface of CNT with methacrylic acid (functional monomer) and ethylene glycol dimethacrylate (crosslinking agent) using a photografting polymerization technique. The adsorbed layer of 2,2-dimethoxy-2-phenylacetophenone initiated a radical polymerization near the surface by UV-light irradiation. The theophylline-imprinted polymer on CNT showed higher binding capacity for theophylline than non-imprinted polymer (NIP) on CNTand selectivity for theophylline over caffeine (similar structure molecules).

In another work (Prasad et al., 2010a), MIP-carbon composite is prepared via in situ free radical polymerization of a synthetic monomer and subsequent crosslinkage with ethylene glycol dimethacrylate, in the presence of carbon powder and folic acid as template. The detection of folic acid with the MIP fiber sensor was found to be specific and quantitative in aqueous, blood serum and pharmaceutical samples, without any problem of nonspecific false positive contribution and crossreactivity.

An insulin imprinted polymer (Prasad et al., 2010b) was synthesized over the surface of vinyl group functionalized MWCNTs using phosphotidylcholine containing functional monomer and crosslinker. Phosphotidylcholine is a major component of all biological membrane; its incorporation in polymer backbone assures water compatibility, biocompatibility and specificity to molecularly imprinted nanomaterials, without any crossreactivity or interferences from biological sample matrices. An electrochemical sensor fabricated by modifying multiwalled carbon nanotubes molecularly imprinted polymer onto the pencil graphite electrode, was used for trace level detection of insulin in aqueous, blood serum, and pharmaceutical samples by differential pulse anodic stripping voltammetry.

A sensitive molecularly imprinted electrochemical sensor has been developed in Huang J. et al., 2011a for the selective detection of tyramine by combination of MWCNTs-gold nanoparticle composites and chitosan. Chitosan acts as a bridge for the imprinted layer and the nanocomposites. The molecularly imprinted polymer (MIP) was synthesized using tyramine as the template molecule, silicic acid tetracthyl ester and triethoxyphenylsilane as the functional monomers. The molecularly imprinted film displayed excellent selectivity towards tyramine. A thymidine sensor (Zhang Z.H. et al., 2010) was developed by casting thin film of molecularly imprinted sol-gel polymers with specific binding sites for thymidine on carbon electrode by electrochemical deposition. The excellent performance of the imprinted sol-gel/MWCNTs electrode towards thymidine can be ascribed to the MWCNTs functional layer with electrochemical catalytic activities and the porous imprinted film with plentiful selective binding sites. Under the optimized analytical conditions, the peak current was linear to thymidine concentration from 2 to $22 \mu \mathrm{mol}^{-1}$ with the detection limit of $1.610^{-9} \mathrm{~mol} \mathrm{~L}^{-1}$.

A different MWNTs-MIPs composites was prepared by using dopamine as a template molecule by the selective copolymerization of methacrylic acid and trimethylolpropane trimethacrylate in the presence of the template and vinyl group functionalized MWNT surface (Kan et al., 2008b). In this work, for grafting MIPs on MWNTs, the vinyl group was first introduced on the surface of MWNTs, which directed the selective polymerization of functional monomers and cross linkers in the presence of DA on the MWNTs surface. The thickness of the MIPs can be adjusted by changing the concentration 
of prepolymerization monomers. The resulting MWNTs-MIPs possessed a faster adsorption dynamics, higher selectivity for the template. The modified electrode fabricated by modifying the MWNTs-MIPs on the glassy carbon electrode can recognize dopamine with a linear range from $5.010^{-7}$ to $2.010^{-4} \mathrm{~mol} / \mathrm{L}$.

A sensor for the detection of Uric acid was proposed in (Yu J.C.C. \& Lai, 2006) by polymerization of polymethacrylic acid on the surface of vinyl-functionalized CNTs in the presence of the template. The MIP adsorbs more Uric acid than NIP and the imprinting efficiency was found to be about 4.41. The MIP modified MWCNTs can be deposited on the MWCNTs electrode surface and used for the electrochemical detection for the template. The differences of adsorption amounts between MIP and NIP electrodes were determined by CVs with different adsorption times. The adsorption reached saturation after $5 \mathrm{~min}$ of adsorption and the result was close to the rebinding experiments. The sensitivities of the MIP and NIP modified electrodes were about 11.03 and $5.39 \mathrm{mAM}^{-1} \mathrm{~cm}^{-2}$, respectively, and the difference mainly came from the affinity cavities which were created by the imprinted template.

A novel protein molecularly imprinted membrane (PMIM) was synthesized in Zhang M. et al., 2010 on the surface of MWNTs through a surface molecular imprinting technique by using bovine serum albumin as the template molecule, acrylamide as the functional monomer, N,N'methylenebisacrylamide as the crosslinker. The selectivity adsorption experiments showed that the PMIM/MWNTs also had higher adsorption capacities for BSA than for such molecules, as HSA, HB, pepsin and HRP. The PMIM/MWNTs displayed a 2.6 fold increase in affinity to BSA compared to the nPMIM/MWNTs. The PMIM/MWNTs, on the other hand, did not exhibit any significant change in affinity to other molecules compared to the nPMIM/MWNTs.

An estrone sensor was developed in Gao R. et al., 2011 by using a semicovalent imprinting strategy, which employed a thermally reversible covalent bond at the surface of silica coated CNTs. The synthesis of the nanocomposites involves silica shell deposition on the surface of CNTs, MIPs functionalized onto the silica surface, and final extraction of estrone by thermal reaction and generation of the recognition site. Authors state that the core-shell CNTs@MIPs nanocomposites developed in this work can also be applied as a selective coating for electrochemical or quartz crystal microbalance sensors to monitor for estrone residue in environmental water

MIP-CNTs nanocomposites are also proposed as innovative drug delivery devices (Yin et al., 2010). MIP nanotubes were fabricated by atom transfer radical polymerization (ATRP) and applied in enantioselective drug delivery and controlled release. Authors found that Spropranolol imprinted nanotubes provided differential release of enantiomers, whereby the release of the more therapeutically active S-propranolol (eutomer) is greatly promoted whilst the release of the less active R-enantiomer (distomer) is retarded.

In environmental field, a recent work (Zhang Z. et al., 2010c) a novel MIPs with core-shell structure is fabricated by using MWNTs as the core material. Prior to polymerization, the silicon-oxygen group was grafted onto the MWNTs surface, then silicon-oxygen groups grafted onto the MWNTs surface could copolymerize directly with functional monomers and crosslinkers in the presence of the template molecules by hydrolysis and condensation, which can lead to the formation of MIPs on the surface of MWNTs. The imprinted material, 
which showed a good selective recognition to Sudan IV with Qmax of $63.2 \mathrm{mmol} \mathrm{g}^{-1}$, was applied as sorbets for the enrichment and determination of trace Sudan IV in real samples by online SPE-HPLC.

CNTs were used successfully to enhance the binding capacity of a molecularly imprinted polypyrrole modified stainless steel frit for determination of ochratoxin A in red wines $\mathrm{Yu}$ J.C.C. \& Lai, 2007; Wei et al., 2007). In a different work (Li Y. et al., 2010), a molecularly imprinted polymer-graphene oxide hybrid material was synthesized by reversible addition and fragmentation chain transfer (RAFT) polymerization for the selective detection of 2,4dichlorophenol in aqueous solution with an appreciable selectivity over structurally related compounds.

Diaz-Diaz et al., 2011 describes an electrochemical sensors based on a catalytic 2,4,6trichlorophenol molecularly imprinted microgel that mimics the dehalogenative function of the natural enzyme chloroperoxidase for p-halophenols. Two strategies were explored: a carbon paste modified with the polymer and the drop-coating of screen-printed electrodes with powder suspensions of the polymer and carbon nanotubes. With this last design, 2,4,6trichlorophenol concentrations above $25 \mathrm{mM}$ could be detected.

In similar studies, an electrochemical imprinted sensor for sensitive and convenient determination of Bisphenol A (Huang J. et al., 2011b) and clindamycin (Zhang Z. et al., 2010a) were developed. In both the cases, MWCNTs and gold nanoparticles were introduced for the enhancement of electronic transmission and sensitivity, while thin film of molecularly imprinted sol-gel polymers with specific binding sites for the templates were cast on gold electrode by electrochemical deposition. The resulting composites displayed excellent selectivity towards.

A simple method was developed (Gao R. et al., 2010) to synthesize core-shell molecularly imprinted polymers for the extraction of triclosan with fast kinetics, high capacity and favorable selectivity by combining a surface molecular imprinting technique with a sol-gel process based on carbon nanotubes coated with silica.

By a surface imprinting technique, in Zhang H. et al., 2011, a composite imprinted material, on the basis of a MWCNTs-incorporated layer using melamine as a template, methacrylic acid as a functional monomer, and ethylene glycol dimethacrylate as a cross-linker, was synthesized. In this work, the poly(acrylic-acid)-functionalized CNTs were synthesized to increase the diameter of CNTs. Then, the vinyl group was introduced to the surface of poly(acrylic-acid)-functionalized CNTs by an amidation. Using Melamine as a template molecule, imprinted CNT composite material was fabricated by a thermal polymerization. Applied as a sorbent, the imprinted materials were used for the determination of Melamine in the spiked sample by online SPE combined with HPLC.

By the same approach, Ga(III)imprinted-CNTs sorbent was prepared in Zhang Z. et al., 2010d by using $\mathrm{Ga}(\mathrm{III})$ ion-8hydroxyquinoline complex as a template molecule. The imprinted sorbent was applied successfully for extraction of $\mathrm{Ga}(\mathrm{III})$ ion from fly ash lixivium followed by FAAS detection. Authors state that compared with the others literature methods for Ga determination, their method is sufficiently accurate and precise to be used for $\mathrm{Ga}(\mathrm{III})$ ion analysis in fly ash samples, and performed better characteristics such as selectivity and cleanliness of the extracts. 


\section{Acknowledgements}

Authors are solely responsible for this work. Financial support of Regional Operative Program (ROP) Calabria ESF 2007/2013 - IV Axis Human Capital - Operative Objective M2 - Action D.5 is gratefully acknowledged.

\section{References}

Adbo, K. \& Nicholls, I.A. (2001). Enantioselective solid-phase extraction using Troger's base molecularly imprinted polymers. Analytica Chimica Acta, 435, 115-120.

Adhikari, B. \& Majumdar, S. (2004) Polymers in sensor applications. Progress in Polymer Science, 29, 699- 766.

AguilarArteaga, K.; Rodriguez, J.A. \& Barrado, E. (2010). Magnetic solids in analytical chemistry: A review. Analytica Chimica Acta, 674, 157-165.

Ajayan, P.M.; Lambert, J.M.; Bernier, P.; Barbedette, L.; Colliex, C. \& Planeix, J.M. (1993). Growth morphologies during cobalt-catalyzed single-shell carbon nanotube synthesis. Chemical Physics Letters, 215, 509-517.

Alizadeh, T.; Ganjali, M.R.; Zare, M. \& Norouzi, P. (2010). Development of a voltammetric sensor based on a molecularly imprinted polymer (MIP) for caffeine measurement. Electrochimica Acta, 55, 1568-1574.

Anderson, C.D.; Shea, K.J. \& Rychnovsky, S.D. (2005). Strategies for the generation of molecularly imprinted polymeric nitroxide catalysts. Organic Letters, 7, 4879-4882.

Andersson, L.I.; Miyabayashi, A.; O'Shannessy, D.J. \& Mosbach, K. (1990). Enantiomeric resolution of amino acid derivatives on molecularly imprinted polymers as monitored by potentiometric measurements. Journal of Chromatography, 516, 323331.

Ando, Y. \& Iijima, S. (1993). Preparation of Carbon Nanotubes by Arc-Discharge Evaporation. Japanese Journal of Applied Physics, 32, L107-L109.

Ando, Y. (1993). Carbon Nanotubes at As-Grown Top Surface of Columnar Carbon Deposit. Japanese Journal of Applied Physics, 32, L1342-L1345.

Ando, Y.; Zhao, X.; Sugai, T. \& Kumar, M. (2004). Growing carbon nanotubes. Materials Today, 7, 22-29.

Aponte, V.M.; Finch, D.S. \& Klaus, D.M. (2006). Considerations for non-invasive in-flight monitoring of astronaut immune status with potential use of MEMS and NEMS devices. Life Sciences, 79, 1317-1333.

Artyukhin, A.B.; Bakajin, O.; Stroeve, P. \& Noy, A. (2004). Layer-by-Layer Electrostatic SelfAssembly of Polyelectrolyte Nanoshells on Individual Carbon Nanotube Templates. Langmuir, 20, 1442-1448.

Atesa, M. \& Sarac A.S. (2009). Conducting polymer coated carbon surfaces and biosensor applications. Progress in Organic Coatings, 66, 337-358.

Augusto, F.; Carasek, E.; Costa Silva, R.G.; Rivellino, S.R.; Batista, A.D. \& Martendal E. (2010). New sorbents for extraction and microextraction techniques. Journal of Chromatography A, 1217, 2533-2542.

Ausman, K.; Piner, R., Lourie, O. \& Ruoff, R. (2000). Organic solvent dispersion of singlewalled carbon nanotubes: towards solutions of pristine nanotubes. Journal of Physical Chemistry B, 104, 8911-8915. 
Bahun, G.J.; Wang, C. \& Adronov, A. (2006). Solubilizing single-walled carbon nanotubes with pyrene-functionalized block copolymers. Journal of Polymer Science, Part A: Polymer Chemistry, 44, 1941-1951.

Bai, J.B. \& Allaoui, A. (2003). Effect of the length and the aggregate size of MWNTs on the improvement efficiency of the mechanical and electrical properties of nanocomposites experimental investigation. Composites Part A, 34, 689-694.

Bakker, E. \& Qin, Y. (2006). Electrochemical Sensors. Analytical Chemistry, 78, 3965-3983.

Balasubramanian, K. \& Burghard, M. (2005). Chemically Functionalized Carbon Nanotubes. Small, $1180-192$.

Balasubramanian, K.; Burghard, M. \& Kern, K. (2004). In: Dekker Encyclopedia of Nanoscience and Nanotechnology, J.A. Schwarz, C.I. Contescu \& K. Putyera, 507-517, Marcel Dekker, New York.

Banholzer, M.J.; Millstone, J.E.; Qin, L.D. \& Mirkin, C.A. (2008). Rationally designed nanostructures for surface-enhanced raman spectroscopy. Chemical Society Reviews, 37, 885-897.

Basabe-Desmonts, L.; Reinhoudt, D.N. \& Crego-Calama, M. (2007). Design of fluorescent materials for chemical sensing. Chemical Society Reviews, 36, 993-1017.

Baskaran, D., Mays, J.W. \& Bratcher, M.S. (2004). Polymer-Grafted Multiwalled Carbon Nanotubes through Surface-Initiated Polymerization. Angewandte Chemie International Edition in English, 43, 2138-2142.

Bauer, L.A.; Birenbaum, N.S. \& Meyer, G.J. (2004). Biological applications of high aspect ratio nanoparticles. Journal of Materials Chemistry, 14, 517-526.

Bauhofer, W. \& Kovacs, J.Z. (2009). A review and analysis of electrical percolation in carbon nanotube polymer composites. Composites Science and Technology, 69, 1486-1498.

Bekyarova, E.; Davis, M.; Burch, T.; Itkis, M. E.; Zhao, B.; Sunshine, S. \& Haddon, R.C. (2004). Chemically Functionalized Single-Walled Carbon Nanotubes as Ammonia Sensors. Journal of Physical Chemistry B, 108, 19717-19720.

Bethune, D.S.; Johnson, R.D.; Salem, J.R.; de Vries, M.S. \& Yannoni, C.S. (1993). Atoms in carbon cages: the structure and properties of endohedral fullerenes. Nature, 366, 123-128.

Bianco, A., Kostarelos. K.; Partidos, C.D. \& Prato, M. (2005). Biomedical applications of functionalised carbon nanotubes. Chemical Communications, 5, 571-577.

Bianco, A.; Kostarelos, K. \& Prato, M. (2005). Applications of carbon nanotubes in drug delivery. Current Opinion in Chemical Biology, 9, 674-679.

Bongaers, E.; Alenus, J.; Horemans, F.; Weustenraed, A.; Lutsen, L.; Vanderzande, D.; Cleij, T.J.; Troost, G.J.; Brummer, R.-J. \& Wagner, P. (2010). A MIP-based biomimetic sensor for the impedimetric detection of histamine in different $\mathrm{pH}$ environments. Physica Status Solidi (A) Applications and Materials, 207, 837-843.

Breuer, O. \& Sundararaj, U. (2004). Big returns from small fibers: a review of polymer/carbon nanotube composites. Polymer Composites, 25, 630-645.

Bryning, M.B.; Islam, M.F.; Kikkawa, J.M. \& Yodh, A.G. (2005). Very low conductivity threshold in bulk isotropic single walled carbon nanotube epoxy composites. Advanced Materials, 17, 1186-1191. 
Buffa, F.; Hu, H. \& Resasco, D.E. (2005). Side-Wall Functionalization of Single-Walled Carbon Nanotubes with 4-Hydroxymethylaniline Followed by Polymerization of $\varepsilon$ Caprolactone. Macromolecules, 38, 8258-8263.

Byrne, M.E. \& Salian, V. (2008). Molecular imprinting within hydrogels II: progress and analysis of the field. International Journal of Pharmaceutics, 364, 188-212.

Cai, Y.; Jiang, G.; Liu, J. \& Zhou, Q. (2003a). Multi walled carbon nanotubes as a solid-phase extraction adsorbent for the determination of bisphenol a, 4-n-nonylphenol, and 4tert-octylphenol. Analytical Chemistry, 75, 2517-2521.

Cai, Y.; Jiang, G.; Liu, J. \& Zhou, Q. (2003b). Multi-walled carbon nanotubes packed cartridge for the solid-phase extraction of several phthalate esters from water samples and their determination by high performance liquid chromatography. Analytica Chimica Acta, 494, 149-156.

Caldorera-Moore M. \& Peppas, N.A. (2009). Micro- and nanotechnologies for intelligent and responsive biomaterial-based medical systems. Advanced Drug Delivery Reviews, 61, 1391-1401.

Caro, E.; Masquè, N.; Marcè, R.M.; Borrull, F.; Cormack, P.A.G. \& Sherrington, D.C. (2002). Non-covalent and semi-covalent molecularly imprinted polymers for selective online solid-phase extraction of 4-nitrophenol from water samples. Journal of Chromatography A, 963, 169-178.

Chang, L.; Wu, S.; Chen, S. \& Li, X. (2011). Preparation of graphene oxide-molecularly imprinted polymer composites via atom transfer radical polymerization. Journal of Materials Science, 46, 2024-2029.

Chen, J.R.; Miao, Y.Q.; He, N.Y.; Wu, X.H. \& Li, S.J. (2004). Nanotechnology and biosensors. Biotechnology Advances, 22, 505-518.

Chen, S.M.; Chen, D.Y. \& Wu, G.Z. (2006). Grafting of Poly(tBA) and PtBA-b-PMMA onto the Surface of SWNTs Using Carbanions as the Initiator. Macromolecular Rapid Communications, 27, 882-887.

Chen, Z.; Zhang, L.Y. \& Chen, G. (2009). Carbon nanotube/poly(ethylene-co-vinyl acetate) composite electrode for capillary electrophoretic determination of esculin and esculetin in Cortex Fraxini. Electrophoresis, 30, 3419-3426.

Cheng, H.M.; Li, F.; Sun, X.; Brown, S.D.M.; Pimenta, M.A.; Marucci, A.; Dresselhaus, G. \& Dresselhaus, M.S. (1998). Bulk morphology and diameter distribution of singlewalled carbon nanotubes synthesized by catalytic decomposition of hydrocarbons. Chemical Physics Letters, 289, 602-610.

Choi, E.S.; Brooks, J.S.; Eaton, D.L.; Al Haik, M.S.; Hussaini, M.Y.; Garmestani, H.; Li, D. \& Dahmen, K. (2003). Enhancement of thermal and electrical properties of carbon nanotube polymer composites by magnetic field processing. Journal of Appled Physics, 94, 6034-6039.

Cirillo, G.; Curcio, M.; Parisi, O.I.; Puoci, F.; Iemma, F.; Spizzirri, U.G.; Restuccia, D. \& Picci, N. (2011a). Molecularly Imprinted Polymers for the Selective Extraction of Glycyrrhizic acid from Liquorice Roots. Food Chemistry, 125, 1058-1063.

Cirillo, G.; Hampel, S.; Klingeler, R.; Puoci, F.; Iemma, F.; Curcio, M.; Parisi, O.I.; Spizzirri, U.G.; Picci, N.; Leonhardt, A.; Ritschel, M. \& Büchner, B. (2011b). Antioxidant Multi-Walled Carbon Nanotubes by Free Radical Grafting of Gallic acid: new 
materials for biomedical applications. Journal of Pharmacy and Pharmacology. 63, 179188.

Cirillo, G.; Parisi, O.I.; Curcio, M.; Puoci, F.; Iemma, F.; Spizzirri, U.G. \& Picci, N. (2010). Molecularly Imprinted Polymers as Drug Delivery Systems for the Sustained Release of Glycyrrhizic acid. Journal of Pharmacy and Pharmacology, 62, 577-582.

Colbert, D.T.; Zhang, J.; McClure, S.M.; Nikolaev, P.; Chen, Z.; Hafner, J.H.; Owens, D.W.; Kotula, P.G.; Carter, C.B.; Weaver, J.H.; Rinzler, A.G. \& Smalley, R.E. (1994). Growth and Sintering of Fullerene Nanotubes. Science, 266, 1218-1222.

Cruz-Vera, M.; Lucena, R.; Cárdenas, S. \& Valcárcel, M. (2010). Highly selective and nonconventional sorbents for the determination of biomarkers in urine by liquid chromatography. Analytical and Bioanalytical Chemistry, 397, 1029-1038.

Cui, D.X. \& Gao, H.J. (2003). Advance and prospect of bionanomaterials. Biotechnology Progress, 19, 683-692.

Cui, H.; Wang, W.P.; You, Y.Z.; Liu, C.H. \& Wang, P.H. (2004). Functionalization of multiwalled carbon nanotubes by reversible addition fragmentation chain-transfer polymerization. Polymer, 45, 8717-8721.

Curcio, M.; Puoci, F.; Cirillo, G.; Iemma, F.; Spizzirri, U.G. \& Picci, N. (2010). Selective Determination of Melamine in Aqueous Medium by Molecularly Imprinted Solid Phase Extraction. Journal of Agricultural and Food Chemistry, 58, 11883-11887.

Dai, X.H.; Liu, Z.M.; Han, B.X.; Sun, Z.Y.; Wang, Y.; Xu, J.; Guo, X.L.; Zhao, N. \& Chen, J. (2004). Carbon nanotube/poly(2,4-hexadiyne-1,6-diol) nanocomposites prepared with the aid of supercritical $\mathrm{CO}_{2}$. Chemical Communications, 19, 2190-2191.

Daniel, S.; Rao, T.P.; Rao, K.S.; Rani, S.U.; Naidu, G.R.K.; Lee, H.Y. \& Kawai, T. (2007). A review of DNA functionalized/grafted carbon nanotubes and their characterization. Sensors and Actuators, B, 122, 672-682.

Davis, J.J.; Coleman, K.S.; Azamian, B.R.; Bagshaw, C.B. \& Green, M.L.H. (2003). Chemical and Biochemical Sensing with Modified Single Walled Carbon Nanotubes. Chemistry A European Journal, 9, 3732-3739.

Deore, B.; Chen, Z.D. \& Nagaoka, T. (2000). Potential-Induced Enantioselective Uptake of Amino Acid into Molecularly Imprinted Overoxidized Polypyrrole. Analytical Chemistry, 72, 3989-3994.

Desai, T.A. (2000). Micro- and nanoscale structures for tissue engineering constructs. Medical Engineering and Physics, 22, 595-606.

Diaz-Diaz, G.; Blanco-Lopez, M.C.; Lobo-Castanon, M.J.; Miranda-Ordieres, A.J. \& TunonBlanco, P. (2011). Preparation and Characterization of a Molecularly Imprinted Microgel for Electrochemical Sensing of 2,4,6-Trichlorophenol. Electroanalysis, 23, 201-208.

Dresselhaus, M.S.; Dresselhaus, G.; Charlier, J.C. \& Hernandez, E. (2004). Electronic, thermal and mechanical properties of carbon nanotubes. Philosophical Transactions of the Royal Society A: Mathematical, Physical and Engineering Sciences, 362, 2065-2098.

Dyke, C.A. \& Tour, J.M. (2004). Overcoming the insolubility of carbon nanotubes through high degrees of sidewall functionalization. Chemistry, 10, 812-817.

Ebbesen, T.W. \& Ajayan, P.M. (1992). Large-scale synthesis of carbon nanotubes. Nature, $358,220-222$.

Eggins, B.R. (2002). Chemical sensors and biosensors. John Wiley, Chichester, UK. 
El-Sheikh, A.H.; Al-Quse, R.W.; El-Barghouthi, M.I. \& Al-Masri, F.S. (2010). Derivatization of 2-chlorophenol with 4-amino-anti-pyrine: A novel method for improving the selectivity of molecularly imprinted solid phase extraction of 2-chlorophenol from water. Talanta, 83, 667-673.

Endo, M.; Takeuchi, K.; Igarashi, S.; Kobori, K.; Shiraishi, M. \& Kroto, H.W. (1993). The production and structure of pyrolytic carbon nanotubes (PCNTs). Journal of Physics and Chemistry of Solids, 54, 1841-1848.

Fang, G.; He, J. \& Wang, S. (2006). Multiwalled carbon nanotubes as sorbent for on-line coupling of solid-phase extraction to high-performance liquid chromatography for simultaneous determination of 10 sulfonamides in eggs and pork. Journal of Chromatography A, 1127, 12-17.

Fangming, D.; Fisher, J.E. \& Winey, K.I. (2003). Coagulation method for preparing single walled carbon nanotube/poly(methyl methacrylate) composites and their modulus, electrical conductivity, and thermal stability. Journal of Polymer Science Part B, Polymer Physics, 41, 3333-3338.

Feng, F.D.; He, F.; An, L.L.; Wang, S.; Li, Y.H. \& Zhu, D.B. (2008). Fluorescent conjugated polyelectrolytes for biomacromolecule detection. Advanced Materials, 20, 2959-2964.

Fernando, K.A.; Lin, Y. \& Sun, Y.P. (2004). High aqueous solubility of functionalized singlewalled carbon nanotubes. Langmuir, 20, 4777-4778.

Flahaut, E.; Govindaraj, A.; Peigney, A.; Laurent, Ch.; Rousset, A. \& Rao, C.N.R. (1999). Synthesis of single-walled carbon nanotubes using binary ( $\mathrm{Fe}, \mathrm{Co}, \mathrm{Ni}$ ) alloy nanoparticles prepared in situ by the reduction of oxide solid solutions. Chemical Physics Letters, 300, 236-242.

Flavel, B.S.; Yu, J.X.; Shapter, J.G. \& Quinton, J.S. (2009). Patterned polyaniline \& carbon nanotube-polyaniline composites on silicon. Soft Matter, 5, 164-172.

Foldvari, M. \& Bagonluri, M. (2008). Carbon nanotubes as functional excipients for nanomedicines: I. pharmaceutical properties. Nanomedicine: Nanotechnology, Biology, and Medicine, 4, 173-182.

Fontanals, N.; Marcé, R.M. \& Borrull, F. (2007). New materials in sorptive extraction techniques for polar compounds Journal of Chromatography A, 1152, 14-31.

Frost, N.W.; Jing, M. \& Bowser, M.T. (2010). Capillary Electrophoresis. Analytical Chemistry, $82,4682-4698$.

Fu, K. \& Sun, Y.P. (2003). Dispersion and solubilization of carbon nanotubes. Journal of Nanoscience and Nanotechnology, 3, 351-364.

Gao, C.; Jin, Y.Z.; Kong, H.; Whitby, R.L.D.; Acquah, S.F.A.; Chen, G.Y.; Qian, H.H.; Hartschuh, A.; Silva, S.R.P.; Henley, S.; Fearon, P.; Kroto, H.W. \& Walton, D.R.M. (2005). Polyurea-Functionalized Multiwalled Carbon Nanotubes: Synthesis, Morphology, and Raman Spectroscopy. Journal of Physical Chemistry B, 109, 1192511932.

Gao, C.; Muthukrishnan, S.; Li, W.; Yuan, J.; Xu, Y. \& Mu1ller, A.H.E. (2007). Linear and Hyperbranched Glycopolymer-Functionalized Carbon Nanotubes: Synthesis, Kinetics, and Characterization. Macromolecules, 40, 1803-1815.

Gao, D.; Zhang, Z.; Wu, M.; Xie, C.; Guan, G. \& Wang, D. (2007). A surface functional monomer-directing strategy for highly dense imprinting of TNT at surface of silica nanoparticles. Journal of the American Chemical Society, 129, 7859-7866. 
Gao, J.B.; Itkis, M.E.; Yu, A.P.; Bekyarova, E.; Zhao, B. \& Haddon, R.C. (2005). Continuous Spinning of a Single-Walled Carbon Nanotube-Nylon Composite Fiber. Journal of the American Chemical Society, 127, 3847-3854.

Gao, R.; Kong, X.; Su, F.; He, X.; Chen, L. \& Zhang, Y. (2010). Synthesis and evaluation of molecularly imprinted core-shell carbon nanotubes for the determination of triclosan in environmental water samples. Journal of Chromatography A, 1217, 80958102.

Gao, R.; Su, X.; He, X.; Chen, L. \& Zhang, Y. (2011). Preparation and characterisation of coreshell CNTs@MIPs nanocomposites and selective removal of estrone from water samples. Talanta,83, 757-764.

Garreau, D.; Hapiot, P. \& Saveant, J.M. (1990). Fast cyclic voltammetry at ultramicroelectrodes: Current measurement and ohmic drop positive positive feedback compensation by means of current feedback operational amplifiers. Journal of Electroanalytical Chemistry and Interfacial Electrochemistry, 281, 73-83.

Geng, H.Z.; Zhang, X.B.; Mao, S.H.; Kleinhammes, A.; Shimoda, H.; Wu, Y. \& Zhou, O. (2004). Opening and closing of single-wall carbon nanotubes. Chemical Physics Letters, 399, 109-113.

Georgakilas, V.; Kordatos, K.; Prato, M.; Guldi, D.M.; Holzingger, M. \& Hirsch, A. (2002). Organic functionalization of carbon nanotubes. Journal of the American Chemical Society, 124, 760-761.

Gigliotti, B.; Sakizzie, B.; Bethune, D.S.; Shelby, R.M. \& Cha, J.N. (2006). Sequence independent helical wrapping of single-walled carbon nanotubes by long genomic DNA. Nano Letters, 6, 159-164.

Gomez, F.J.; Chen, R.J.; Wang, D.W.; Waymouth, R.M. \& Dai, H.J. (2003). Ring opening metathesis polymerization on non-covalently functionalized single-walled carbon Nanotubes. Chemical Communications, 2, 190-191.

Gooding, J.J.; R. Wibowo, Liu, J.; Yang, W.; Losic, D.; Orbons, S.; Mearns, F.J.; Shapter, J.G. \& Hibbert, D.B. (2003). Protein Electrochemistry Using Aligned Carbon Nanotube Arrays. Journal of the American Chemical Society, 125, 9006-9007.

Guan, G.; Liu, B.; Wang, Z. \& Zhang, Z. (2008). Imprinting of Molecular Recognition Sites on Nanostructures and its Applications in Chemosensors. Sensors, 8, 8291-8320.

Guiseppi-Elie, A.; Lei, C. \& Baughman, R.H. (2002). Direct electron transfer of glucose oxidase on carbon nanotubes. Nanotechnology, 13, 559-564.

Guo, M.; Chen, J.; Liu, D.; Nie, L. \& Yao, S. (2004). Electrochemical characteristics of the immobilization of calf thymus DNA molecules on multi-walled. Bioelectrochemistry, 62, 29-35.

Guo, T.; Diener, M.D.; Chai, Y.; Alford, M.J.; Haufler, R.E.; McClure, S.M.; Ohno, T.; Weaver, J.H.; Scuseria, G.E. \& Smalley, R.E. (1992). Uranium Stabilization of C28: A Tetravalent Fullerene. Science, 257, 1661-1164.

Hafner, J.H.; Bronikowski, M.J.; Azamian, B.R.; Nikolaev, P.; Rinzler, A.G.; Colbert, D.T.; Smith, K.A. \& Smalley, R.E. (1998). Catalytic growth of single-wall carbon nanotubes from metal particles. Chemical Physics Letters, 296, 195-202.

Ham, H.T.; Choi, Y.S.; Chung, I.J. (2005). An explanation of dispersion states of singlewalled carbon nanotubes in solvents and aqueous surfactant solutions using solubility parameters. Journal of Colloid and Interface Science, 286, 216-223. 
Haupt K. (2003). Imprinted polymers - Tailor-made mimics of antibodies and receptors. Chemical Communications, 2, 171-178.

Haupt, K. \& Mosbach, K. (2000). Molecularly imprinted polymers and their use in biomimetic sensors. Chemical Revies 100, 2495-2504.

He, P.G. \& Bayachou, M. (2005). Layer-by-Layer Fabrication and Characterization of DNAWrapped Single-Walled Carbon Nanotube Particles. Langmuir, 21, 6086-6092.

Hernadi, K.; Fonseca, A.; Nagy, J.B.; Bernaerts, D. \& Lucas, A.A. (1996). Fe-catalyzed carbon nanotube formation. Carbon, 34, 1249-1257.

Hillberg, A.L.; Brain, K.R. \& Allender, C.J. (2005). Molecular imprinted polymer sensors: Implications for therapeutics. Advanced Drug Delivery Reviews, 57, 1875-1889.

Hilt, J.Z. \& Byrne, M.E. (2004). Configurational biomimesis in drug delivery: molecular imprinting of biologically significant molecules. Advanced Drug Delivery Reviews, 56, 1599-1620.

Hishiya, T.; Asanuma, H. \& Komiyama, M. (2003). Molecularly imprinted cyclodextrin polymers as stationary phases of high performance liquid chromatography. Polymer Journal, 35, 440-445.

Hong, C.Y.; You, Y.Z. \& Pan, C.Y. (2005). Synthesis of Water-Soluble Multiwalled Carbon Nanotubes with Grafted Temperature-Responsive Shells by Surface RAFT Polymerization. Chemistry of Materials, 17, 2247- 2254.

Hong, C.Y.; You, Y.Z. \& Pan, C.Y. (2006). Functionalized multi-walled carbon nanotubes with poly(N-(2-hydroxypropyl)methacrylamide) by RAFT polymerization. Journal of Polymer Science, Part A: Polymer Chemistry, 44, 2419-2427.

Howell, J.O. \& Wightman, R.M. (1984). Ultrafast voltammetry and voltammetry in highly resistive solutions with microvoltammetric electrodes. Analytical Chemistry, 56, 524529.

Hrapovic, S.; Liu, Y.; Male, K.B. \& Luong, J.H.T. (2004). Electrochemical Biosensing Platforms Using Platinum Nanoparticles and Carbon Nanotubes Analytical Chemistry, 76, 1083-1088.

Hsueh, C.C. \& Brajter-Toth, A. (1993). Fast-scan voltammetry in aqueous solutions at carbon fiber ultramicroelectrodes with on-line iR compensation. Analytical Chemistry, 65, 1570-1575.

Hua, G.; Sun, Y.; Gaur, A.; Meitl, M.A.; Bilhaut, L.; Rotkina, L.; Wang, J.; Geil, P.; Shim, M.; Rogers, J.A. \& Shim, A. (2004). Polymer Imprint Lithography with Molecular-Scale Resolution. Nano Letters, 4, 2467-2471.

Huang, H.M.; Liu, I.C.; Chang, C.Y.; Tsai, H.C.; Hsu, C.H. \& Tsiang, R.C.C. (2004). Preparing a polystyrene-functionalized multiple-walled carbon nanotubes via covalently linking acyl chloride functionalities with living polystyryllithium. Journal of Polymer Science, Part A: Polymer Chemistry, 42, 5802-5810.

Huang, J.; Xing, X.; Zhang, X.; He, X.; Lin, Q.; Lian, W. \& Zhu, H. (2011a).A molecularly imprinted electrochemical sensor based on multi walled carbon nanotube-gold nanoparticle composites and chitosan for the detection of tyramine. Food Research International, 44, 276-281.

Huang, J.; Zhang, X.; Lin, Q.; He, X.; Xing, X.; Huai, H.; Lian, W. \& Zhu, H. (2011b). Electrochemical sensor based on imprinted solegel and nanomaterials. Food Control, 22, 786-791. 
Huang, W.; Fernando, S.; Allard, L.F. \& Sun, Y.P. (2003). Solubilization of Single-Walled Carbon Nanotubes with Diamine-Terminated Oligomeric Poly(ethylene Glycol) in Different Functionalization Reactions. Nano Letters, 3, 565-568.

Hwang, C.C. \& Lee, W.C. (2002). Chromatographic characteristics of cholesterol-imprinted polymers prepared by covalent and non-covalent imprinting methods. Journal of Chromatography A, 962, 69-78.

Iijima, S. \& Ichihashi, T. (1993). Single-shell carbon nanotubes of 1nm diameter. Nature, 363, 603-605.

Iijima, S. (1991). Helical microtubules of graphitic carbon. Nature, 354, 56-58.

Ikegami, T.; Mukawa, T.; Nariai, H. \& Takeuchi, T. (2004). Bisphenol A-recognition polymers prepared by covalent molecular imprinting. Analytica Chimica Acta, 504, 131-135.

Islam, M.; Rojas, R.; Bergey, D.; Johnson, A. \& Yodh, A. (2003). High weight fraction surfactant solubilization of single-wall carbon nanotubes in water. Nano Letters, 3 , 269-273.

Jiang, H. \& Ju, H.X. (2007). Enzyme-quantum dots architecture for highly sensitive electrochemiluminescenece biosensing of oxidase substrates. Chemical Communications, 4, 404-406.

Joselevich E. (2004). Electronic structure and chemical reactivity of carbon nanotubes: a chemist's view. Chemphyschem, 5, 619-624.

José-Yacamán, M.; Miki-Yoshida, M.; Rendón, L. \& Santiesteban, J. G. (1993). Catalytic growth of carbon microtubules with fullerene structure. Applied Physics Letters, 62, 657-659.

Joshi, V.P.; Karode, S.K.; Kulkarni, M.G. \& Mashelkar, R.A. (1998). Novel separation strategies based on molecularly imprinted adsorbents. Chemical Engineering Science, 53, 2271-2284.

Kahn, M.G.C.; Banerjee, S. \& Wong, S.S. (2002). Solubilization of Oxidized Single-Walled Carbon Nanotubes in Organic and Aqueous Solvents through Organic Derivatization. Nano Letters, 2, 1215-1218.

Kan, X.; Geng, Z.; Wang, Z. \& Zhu, J.-J. (2009). Core-Shell molecularly imprinted polymer nanospheres for the recognition and determination of hydroquinone. Journal of Nanoscience and Nanotechnology, 9, 2008-2013.

Kan, X.; Liu, T.; Zhou, H.; Li, C. \& Fang, B. (2010). Molecular imprinting polymer electrosensor based on gold nanoparticles for theophylline recognition and determination. Microchimica Acta, 171, 423-429.

Kan, X.; Zhao, Q.; Zhang, Z.; Wang, Z. \& Zhu, J.-J. (2008a). Molecularly imprinted polymers microsphere prepared by precipitation polymerization for hydroquinone recognition. Talanta, 75, 22-26.

Kan, X.; Zhao, Y.; Geng, Z.; Wang, Z. \& Zhu, J.J. (2008b). Composites of Multiwalled Carbon Nanotubes and Molecularly Imprinted Polymers for Dopamine Recognition. Journal of Physical Chemistry C, 112, 4849-4854.

Kanai, M., Koshio, A.; Shinohara, H.; Mieno, T.; Kasuya, A.; Ando, Y. \& Zhao, X. (2001). High-yield synthesis of single-walled carbon nanotubes by gravity-free arc discharge. Applied Physics Letters, 79, 2967-2969. 
Kang, J.; Zhang, H.; Wang, Z.; Wu, G. \& Lu, X. (2009). A novel amperometric sensor for salicylic acid based on molecularly imprinted polymer-modified electrodes. Polymer - Plastics Technology and Engineering, 48, 639-645.

Kawagoe, K.T.; Zimmerman, J.B. \& Wightman, R.M. (1993). Principles of voltammetry and microelectrode surface states. Journal of Neuroscience Methods, 48, 225-240.

Kazua, Y. (1999). Hitachi Chemical Technical Report, 32, 7.

Ke, P.C. \& Qiao, R. (2007). Carbon nanomaterials in biological systems. Journal of Physics Condensed Matter,19, 373101.

Kerman, K.; Morita, Y.; Takamura, Y.; Ozsoz, M. \& Tamiya, E. (2004). DNA-Directed Attachment of Carbon Nanotubes for Enhanced Label-Free Electrochemical Detection of DNA Hybridization. Electroanalysis, 16, 1667-1672.

Kikuchi, M.; Ikoma, T.; Itoh, S.; Matsumoto, H.N.; Koyama, Y.; Takakuda, K.; Shinomiya, K. \& Tanaka, J. (2004). Biomimetic synthesis of bone-like nanocomposites using the self-organization mechanism of hydroxyapatite and collagen. Composites Science and Technology, 64, 819-825.

Kim, D.S., Nepal, D. \& Geckeler, K.E. (2005). Individualization of single walled carbon nanotubes: is the solvent important? Small, 1, 1117-1124.

Kim, S.N.; Rusling, J.F. \& Papadimitrakopoulos, F. (2007). Carbon nanotubes for electronic and electrochemical detection of biomolecules. Advanced Materials, 19, 3214-3228.

Klingeler, R. \& Sim, R.B. (2011). Carbon Nanotubes for Biomedical Applications. Springer, Germany.

Klingeler, R.; Hampel, S. \& Büchner, B. (2008). Carbon nanotube based biomedical agents for heating, temperature sensoring and drug delivery. International Journal of Hyperthermia, 24, 496-505.

Kokai, F.; Takahashi, K; Yudasaka, M. \& Iijima, S. (2000). Laser Ablation of Graphite-Co/Ni and Growth of Single-Wall Carbon Nanotubes in Vortexes Formed in an $\mathrm{Ar}$ Atmosphere. Journal of Physical Chemistry B, 104, 6777-6784.

Kolarz, B.N. \& Jakubiak, A. (2008). Catalytic activity of molecular imprinted vinylpyridine/acrylonitrile/ divinylbenzene terpolymers with guanidyl ligands$\mathrm{Cu}(\mathrm{II})$ inside the active centres. Polimery/Polymers, 53, 848-853.

Kong, H.; Gao, C. \& Yan, D. (2004). Controlled Functionalization of Multiwalled Carbon Nanotubes by in Situ Atom Transfer Radical Polymerization. Journal of the American Chemical Society, 126, 412-413.

Kong, H.; Luo, P.; Gao, C. \& Yan, D. (2005). Polyelectrolyte-functionalized multiwalled carbon nanotubes: preparation, characterization and layer-by-layer self-assembly. Polymer, 46, 2472-2485.

Kong, J.; Cassell, A.M. \& Dai, H. (1998). Chemical vapor deposition of methane for singlewalled carbon nanotubes. Chemical Physics Letters, 292, 567-574.

Kong, J.; Chapline, M.G. \& Dai, H. (2001). Functionalized Carbon Nanotubes for Molecular Hydrogen Sensors. Advanced Materials, 13, 1384-1386.

Kong, J.; Franklin, N.R.; Zhou, C.; Chapline, M.G.; Peng, S.; Cho, K. \& Dai, H. (2000). Nanotube Molecular Wires as Chemical Sensors. Science, 287, 622-625.

Kong, Y.; Zhao, W.; Yao, S.; Xu, J.; Wang, W. \& Chen, Z.(2010). Molecularly imprinted polypyrrole prepared by electrodeposition for the selective recognition of tryptophan enantiomers. Journal of Applied Polymer Science, 115, 1952-1957. 
Kriz, D. \& Mosbach, K. (1995). Competitive amperometric morphine sensor-based on an agarose immobilized molecularly imprinted polymer. Analytica Chimica Acta, 300, 71- 75.

Kriz, D.; Ramström, O.; Svensson, A. \& Mosbach, K. (1995). Introducing biomimetic sensors based on molecularly imprinted polymers as recognition elements. Analytical Chemistry, 67, 2142-2144.

Kröger, S.; Turner, A.P.F.; Mosbach, K. \& Haupt, K. (1999). Imprinted polymer based sensor system for herbicides using differential pulse voltammetry on screen printed electrodes. Analytical Chemistry, 71, 3698- 3702.

Laval, J.M.; Mazeran, P-E. \& Thomas, D. (1999). Nanobiotechnology and its role in the development of new analytical devices. Analyst, 125, 29-33.

Leary, S.P.; Liu, C.Y. \& Apuzzo, M.L. (2006). Toward the emergence of nanoneurosurgery: part III - nanomedicine: targeted nanotherapy, nanosurgery, and progress toward the realization of nanoneurosurgery. Neurosurgery, 58, 1009-1026.

Lee, E.; Park, D.W.; Lee, J.O.; Kim, D.S.; Lee, B.H. \& Kim, B.S. (2008). Molecularly imprinted polymers immobilized on carbon nanotube. Colloids and Surfaces A: Physicochemical and Engineering Aspects, 313-314, 202-206.

Lee, H.Y. \& Kim, B.S. (2009). Grafting of molecularly imprinted polymers on inifertermodified carbon Nanotube. Biosensors and Bioelectronics, 25, 587-591.

Lemos, V.A.; Sena Gomes Teixeira, L.; Almeida Bezerra, M.; Spınola Costa, A.C.; Teixeira Castro, J.; Cardoso, L.A.M.; Santiago de Jesus, D.; Souza Santos, E.; Xavier Baliza, P. \& Novaes Santos, L. (2008). New Materials for Solid-Phase Extraction of Trace Elements. Applied Spectroscopy Reviews, 43, 303-334.

Li, H.M.; Cheng, F.O.; Duft, A.M. \& Adronov, A. (2005). Functionalization of Single-Walled Carbon Nanotubes with Well-Defined Polystyrene by "Click" Coupling. Journal of the American Chemical Society, 127, 14518-14524.

Li, J.; Kendig, C.E. \& Nesterov, E.E. (2007a). Chemosensory performance of molecularly imprinted fluorescent conjugated polymer materials. Journal of the American Chemical Society, 129, 15911-15918.

Li, J.; Ma, P.C.; Chow, W.S.; To, C.K.; Tang, B.Z. \& Kim, J.K. (2007b). Correlations between percolation threshold, dispersion state, and aspect ratio of carbon nanotubes. Advanced Functional Materials, 17, 3207-3215.

Li, Q.; Yuan, D. \& Lin, Q. (2004). Evaluation of multi-walled carbon nanotubes as an adsorbent for trapping volatile organic compounds from environmental samples. Journal of Chromatography A, 1026, 283-288.

Li, Y.; Li, X.; Dong, C.; Qi, J. \& Han, X. (2010). Graphene oxide-based molecularly imprinted polymer platform for detecting endocrine disrupting chemicals. Carbon, 48, 34273433.

Lin, Y.; Zhou, B.; Fernando, K.A.S.; Allard, L.F. \& Sun, Y.P. (2003). Polymeric Carbon Nanocomposites from Carbon Nanotubes Functionalized with Matrix Polymer. Macromolecules, 36, 7199-7204.

Liu, I.C.; Huang, H.M.; Chang, C.Y.; Tsai, H.C.; Hsu, C.H. \& Tsiang, R.C.C. (2004). Preparing a Styrenic Polymer Composite Containing Well-Dispersed Carbon Nanotubes: Anionic Polymerization of a Nanotube-Bound p-Methylstyrene. Macromolecules, 37, 283-287. 
Liu, M.; Zhu, T.; Li, Z. \& Liu, Z. (2009). One-Step in Situ Synthesis of Poly(methyl methacrylate)-Grafted Single-Walled Carbon Nanotube Composites. Journal of Physical Chemistry C, 113, 9670-9675.

Liu, Y.Q.; Yao, Z.L. \& Adronov, A. (2005). Functionalization of Single-Walled Carbon Nanotubes with Well-Defined Polymers by Radical Coupling. Macromolecules, 38, 1172-1179.

Liu, Z.; Bucknall, D.G. \&Allen, M.G. (2010). Absorption performance of iodixanol-imprinted polymers in aqueous and blood plasma media. Acta Biomaterialia, 6, 2003-2012.

Lou, X.D.; Detrembleur, C.; Pagnoulle, C.; Jerome, R.; Bocharova, V.; Kiriy, A. \& Stamm, M. (2004). Surface Modification of Multiwalled Carbon Nanotubes by Poly(2vinylpyridine): Dispersion, Selective Deposition, and Decoration of the Nanotubes. Advanced. Materials, 16, 2123-2127.

Lu, C.; Chung, Y. \& Chang, K. (2005). Adsorption of trihalomethanes from water with carbon nanotubes. Water Research, 39, 1183-1189.

Lucena, R.; Simonet, B.M.; Cárdenas, S. \& Valcárcel, M. (2011). Potential of nanoparticles in sample preparation. Journal of Chromatography A, 1218, 620-637.

Lundstroem, I.; Shivaraman, S.; Svensson, C. \& Lundkvist, L. (1975). A hydrogen-sensitive MOS field-effect transistor. Applied Physics Letters, 26, 55-57.

Ma, G.P.; Yang, D.Z. \& Nie, J. (2009). Preparation of porous ultrafine polyacrylonitrile (PAN) fibers by electrospinning. Polymers for Advanced Technologies, 20, 147-150.

Ma, P.C.; Siddiqui, N.A.; Marom, G. \& Kim, J.K. (2010). Dispersion and functionalization of carbon nanotubes for polymer-based nanocomposites: A review. Composites A, 41, 1345-1367.

Martin, R.B.; Qu, L.W.; Lin, Y.; Harruff, B.A.; Bunker, C.E.; Gord, J.R.; Allard, L.F. \& Sun, Y P. (2004). Functionalized Carbon Nanotubes with Tethered Pyrenes: Synthesis and Photophysical Properties. Journal of Physical Chemistry B, 108, 11447-11453.

Maruccio, G.; Cingolani, R. \& Rinaldi, R. (2004). Projecting the nanoworld: Concepts, results and perspectives of molecular electronics. Journal of Materials Chemistry, 14, 542-554.

Marx, S.; Zaltsman, A.; Turyan, I. \& Mandler, D. (2004). Parathion Sensor Based on Molecularly Imprinted Sol-Gel Films. Analytical Chemistry, 76, 120-126.

Mazzola, L. (2003). Commercializing nanotechnology. Nature Biotechnology, 21, 1137-1143.

McDonagh, C.; Burke, C.S. \& MacCraith, B.D. (2008). Optical chemical sensors. Chemical Reviews, 108, 400-422.

Mirsky, V.M.; Hirsch, T.; Piletsky, S.A. \& Wolfbeis, O.S. A spreader-bar approach to architecture: formation of stable artificial chemoreceptors. Angewandte Chemie International Edition, 38, 1108-1110.

Moniruzzaman, M. \& Winey, K,I. (2006). Polymer nanocomposites containing carbon nanotubes. Macromolecules, 39, 5194-5205.

Moore, V.; Strano, M.; Haroz, E.; Hauge, R. E. Smalley R. (2003). Individually suspended single-walled carbon nanotubes in various surfactants. Nano Letters, 3, 1379-1382.

Mosbach, K. (2006). The promise of molecular imprinting. Scientific American, 295, 86-91.

Musallam, S.; Bak, M.J.; Troyk, P.R. \& Anderson, R.A.(2007). A floating metal microelectrode array for chronic implantation. Journal of Neuroscience Methods, 160, 122-127.

Mylvaganam, K. \& Zhang, L.C. (2004). Nanotube Functionalization and Polymer Grafting: An ab Initio Study. Journal of Physical Chemistry B, 108, 15009-15012. 
Nicholls, I.A.; Matsui, J.; Krook, M. \& Mosbach, K. (1996). Some recent developments in the preparation of novel recognition systems: A recognition site for the selective catalysis of an aldol condensation using molecular imprinting and specific affinity motifs for alpha-chymotrypsin using a phage display peptide library. Journal of Molecular Recognition, 9, 652-657.

Niemeyer, C.M. (2001). Nanoparticles, Proteins, and Nucleic Acids: Biotechnology Meets Materials Science. Angewandte Chemie International Edition in English, 40, 4128-4158.

Nilsson, C.; Birnbaum, S. \& Nilsson, S. (2007). Use of nanoparticles in capillary and microchip electrochromatography. Journal of Chromatography A, 1168, 212-224.

Nogales, A.; Broza, G.; Roslaniec, Z.; Schulte, K.; Sics, I.; Hsiao, B.S.; Sanz, A.; GarciaGutierrez, M.C.; Rueda, D.R.; Domingo, C. \& Ezquerra, T.A. (2004). Low Percolation Threshold in Nanocomposites Based on Oxidized Single Wall Carbon Nanotubes and Poly (butylene terephthalate). Macromolecules, 37, 7669-7672.

Orellana, G. \& Moreno-Bondi, M.C. (2005). Frontiers in chemical sensors: novel principles and techniques. Springer-Verlag, Berlin.

Ouyang, R.; Lei, J.; Ju, H. \& Xue, Y. (2007). A molecularly imprinted copolymer designed for enantioselective recognition of glutamic acid. Advanced Functional Materials 17, 3223-3230.

Panasyuk, T.L.; Mirsky, V.M.; Piletsky, S.A. \& Wolfbeis, O.S. (1999). Electropolymerized molecularly imprinted polymers as receptor layers in a capacitive chemical sensors. Analytical Chemistry, 71, 4609-4613.

Pantarotto, D.; Partidos, C.D.; Graff, R.; Hoebeke, J.; Briand, J.P.; Prato, M. \& Bianco, A. (2003). Synthesis, structural characterization, and immunological properties of carbon nanotubes functionalized with peptides. Journal of the American Chemical Society, 125, 6160-6164.

Patel, A.K.; Sharma, P.S. \& Prasad, B.B. (2009). Electrochemical sensor for uric acid based on a molecularly imprinted polymer brush grafted to tetraethoxysilane derived sol-gel thin film graphite electrode. Materials Science and Engineering C, 29, 1545-1553.

Peng, H.; Alemany, L.B.; Margrave, J.L. \& Khabashesku, V.N. (2003). Sidewall carboxylic acid functionalization of single-walled carbon nanotubes. Journal of the American Chemical Society, 125, 15174-15182.

Petrov, P.; Lou, X.D.; Pagnoulle, C.; Jerome, C.; Calberg, C. \& Jerome, R. (2004). Functionalization of Multi-Walled Carbon Nanotubes by Electrografting of Polyacrylonitrile. Macromolecular Rapid Communications, 25, 987-990.

Petrov, P.; Stassin, F.; Pagnoulle, C. \& Jerome, R. (2003). Noncovalent functionalization of multi-walled carbon nanotubes by pyrene containing polymers. Chemical Communications, 23, 2904-2905.

Petrovic, M.; Farré, M.; Lopez de Alda, M.; Perez, S.; Postigo, C.; Köck, M.; Radjenovic, J.; Gros, M. \& Barcelo, D. (2010). Recent trends in the liquid chromatography-mass spectrometry analysis of organic contaminants in environmental samples. Journal of Chromatography A, 1217, 4004-4017.

Prasad, B.B.; Madhuri, R.; Tiwari, M.P. \& Sharma, P.S. (2010a). Imprinted polymer-carbon consolidated composite fiber sensor for substrate selective electrochemical sensing of folic acid. Biosensors and Bioelectronics, 25, 2140-2148. 
Prasad, B.B.; Madhuri, R.; Tiwari, M.P. \& Sharma, P.S. (2010b). Imprinting molecular recognition sites on multiwalled carbon nanotubes surface for electrochemical detection of insulin in real samples. Electrochimica Acta, 55, 9146-9156.

Prasad, B.B.; Madhuri, R.; Tiwari, M.P. \& Sharma, P.S. (2010c). Electrochemical sensor for folic acid based on a hyperbranched molecularly imprinted polymer-immobilized sol-gel-modified pencil graphite electrode. Sensors and Actuators, B: Chemical, 146, 321-330.

Prasad, B.B.; Madhuri, R.; Tiwari, M.P. \& Sharma, P.S. (2010d). Enantioselective recognition of d- and l-tryptophan by imprinted polymer-carbon composite fiber sensor. Talanta, 81, 187-196.

Prasad, B.B.; Srivastava, S.; Tiwari, K. \& Sharma, P.S. (2009). Development of uracil and 5fluorouracil sensors based on molecularly imprinted polymer-modified hanging mercury drop electrode. Sensors and Materials, 21, 291-306.

Puoci, F.; Cirillo, G.; Curcio, M.; Iemma, F.; Parisi, O.I.; Spizzirri, U.G. \& Picci, N. (2010). Molecularly Imprinted Polymers (MIPs) in Biomedical Applications. In: Biopolymers, Magdy M. Elnashar, 547-574, Sciyo, Rijeka, Croatia.

Puoci, F.; Cirillo, G.; Curcio, M.; Iemma, F.; Spizzirri, U.G. \& Picci, N. (2007). Molecularly Imprinted Solid Phase Extraction for the selective HPLC determination of atocopherol in Bay Leaves. Analytica Chimica Acta, 2007, 593, 164-170.

Puoci, F.; Cirillo, G.; Curcio, M.; Parisi, O.I.; Iemma, F. \& Picci, N. (2011). Molecularly Imprinted Polymers in Drug Delivery: state of art and future perspectives. Expert Opinion on Drug Delivery, DOI 10.1517/17425247.2011.609166.

Puretzky, A.A. Geohegan, D.B.; Fan, X. \& Pennycook, S.J. (2000). Dynamics of single-wall carbon nanotube synthesis by laser vaporization. Applied Physics A Materials Science Processing, 70, 153-160.

Qin, S.H.; Qin, D.Q.; Ford, W.T.; Herrera, J.E. \& Resasco, D.E. (2004a). Grafting of Poly(4vinylpyridine) to Single-Walled Carbon Nanotubes and Assembly of Multilayer Films. Macromolecules, 37, 9963-9967.

Qin, S.H.; Qin, D.; Ford, W.T.; Resasco, D.E. \& Herrera, J.E. (2004b). Polymer Brushes on Single-Walled Carbon Nanotubes by Atom Transfer Radical Polymerization of nButyl Methacrylate. Journal of the American Chemical Society, 126, 170-176.

Qin, S.H.; Qin, D.Q.; Ford, W.T.; Zhang, Y.J. \& Kotov, N.A. (2005). Covalent Cross-Linked Polymer/Single-Wall Carbon Nanotube Multilayer Films. Chemistry of Materials, 17, 2131-2135.

Qu, L.W.; Martin, R.B.; Huang, W.J.; Fu, K.F.; Zweifel, D.; Lin, Y.; Sun, Y.P.; Bunker, C.E.; Harruff, B.A.; Gord, J.R. \& Allard, L.F. (2002). Interactions of functionalized carbon nanotubes with tethered pyrenes in solution. Journal of Chemical Physics, 117, 80898094.

Qu, L.W.; Veca, L.M.; Lin, Y.; Kitaygorodskiy, A.; Chen, B.L.; McCall, A.M.; Connell, J.W. \& Sun, Y.P. (2005). Soluble Nylon-Functionalized Carbon Nanotubes from Anionic Ring-Opening Polymerization from Nanotube Surface. Macromolecules, 38, 1032810331.

Ramanavicius, A.; Ramanaviciene, A. \& Malinauskas, A. (2006). Electrochemical sensors based on conducting polymer-polypyrrole. Electrochimica Acta, 51, 6025-6037. 
Ramasubramaniam, R.; Chen, J. \& Liu, H. (2003). Homogeneous carbon nanotubepolymer composites for electrical applications. Applield Physics Letters, 83, 2928-2930.

Riskin, M.; Tel-Vered, R.; Bourenko, T.; Granot, E. \& Willner, I. (2008). Imprinting of molecular recognition sites through electropolymerization of functionalized $\mathrm{Au}$ nanoparticles: development of an electrochemical TNT sensor based on $\Pi$-donoracceptor interactions. Journal of the American Chemical Sociery, 130, 15911-15918.

Rubianes, M.D. \& Rivas, G.A. (2003). Carbon nanotubes paste electrode. Electrochemistry Communications, 5, 689-694.

Safarik, I. \& Safarikova, M. (2002). Magnetic nanoparticles and biosciences. Monatshefte Fur Chemie, 133, 737-759.

Sahoo, N.G.; Rana, S.; Cho, J.W.; Li, L. \& Chan, S.H. (2010). Polymer nanocomposites based on functionalized carbon nanotubes. Progress in Polymer Science, 35, 837-867.

Saito, Y.; Inagaki, M.; Shinohara, H.; Nagashima, H.; Ohkohchi, M. \& Ando, M. (1992). Yield of fullerenes generated by contact arc method under He and Ar: dependence on gas pressure. Chemical Physics Letters, 200, 643-648.

Sandler, J.K.W.; Kirk, J.E.; Kinloch, I,A.; Shaffer, M.S.P. \& Windle, A.H. (2003). Ultralow electrical percolation threshold in carbon nanotube epoxy composites. Polymer, 44, 5893-5899.

Sano, M.; Kamino, A.; Okamura, J. \& Shinkai, S. (2001). Self-Organization of PEO-graftSingle-Walled Carbon Nanotubes in Solutions and Langmuir-Blodgett Films. Langmuir, 17, 5125-5128.

Satishkumar, B.C.; Govindaraj, A.; Sen, R. \& Rao, C.N.R. (1998). Single-walled nanotubes by the pyrolysis of acetylene-organometallic mixtures. Chemical Physics Letters, 293, 4752.

Satiskumar, B. C.; Govindaraj, A. \& Rao, C.N.R. (1999). Bundles of aligned carbon nanotubes obtained by the pyrolysis of ferrocene-hydrocarbon mixtures: role of the metal nanoparticles produced in situ. Chemical Physics Letters, 307, 158-162.

See, H.H.; Marsin Sanagi, M.; Ibrahim, W.A. \& Naim, A.A. (2010). Determination of triazine herbicides using membraneprotected carbon nanotubes solid phase membrane tip extraction prior to microliquid chromatography. Journal of Chromatography A, 1217, 1767-1772.

Sen, R.; Ohtsuka, Y.; Ishigaki, T.; Kasuya, D.; Suzuki, S.; Kataura, H. \& Achiba, Y. (2000). Time period for the growth of single-wall carbon nanotubes in the laser ablation process: evidence from gas dynamic studies and time resolved imaging. Chemical Physics Letters, 332, 467-473.

Shaffer, M.S.P. \& Koziol, K. (2002). Polystyrene grafted multi-walled carbon nanotubes. Chemical Communications, 18, 2074-2075.

Shao, D.; Ren, X.; Hu, J.; Chen, Y. \& Wang, X. (2010). Preconcentration of $\mathrm{Pb}^{2+}$ from aqueous solution using poly(acrylamide) and poly(N,Ndimethylacrylamide) grafted multiwalled carbon nanotubes. Colloids and Surfaces A: Physicochemical Engineering Aspects, 360, 74-84.

Shi, F.; Liu, Z.; Wu, G.; Zhang, M.; Chen, H.; Wang, Z.; Zhang, X. \& Willner, I. (2007). Surface Imprinting in Layer-by-Layer Nanostructured Films. Advanced Functional Materials, 17, 1821-1827. 
Shiigi, H.; Okamura, K.; Kijima, D.; Deore, B.; Sree, U. \& Nagaoka, T. (2003). An Overoxidized Polypyrrole/Dodecylsulfonate Micelle Composite Film for Amperometric Serotonin Sensing. Journal of The Electrochemical Society, 150, H119H123.

Shimada, T.; Sugau, T.; Ohno, Y.; Kishimoto, S.; Mizutani, T.; Yoshida, H.; Okazaki, T. \& Shinohara, H. (2004). Double-wall carbon nanotube field-effect transistors: Ambipolar transport Characteristics. Applied Physics Letters, 84, 2412-2414.

Sinha, N. \& Yeow, J. (2005). Carbon nanotubes for biomedical applications. IEEE Transactions on NanoBioscience, 4, 180-195.

Song, Y.S. \& Youn, J.R. (2005). Influence of dispersion states of carbon nanotubes on physical properties of epoxy nanocomposites. Carbon, 43, 1378-1385.

Spitalsky, Z.; Tasis, D.; Papagelis, K. \& Galiotis, C. (2010). Carbon nanotube-polymer composites: Chemistry, processing, mechanical and electrical properties. Progress in Polymer Science, 35, 357-401.

Spivak, D.A. (2005). Optimization, evaluation, and characterization of molecularly imprinted polymers. Advanced Drug Delivery Reviws, 57, 1779-1794.

Sugai, T.; Omote, H.; Bandow, S.; Tanaka, N. \& Shinohara, H. (1999). Production of SingleWall Nanotubes by High-Temperature Pulsed Arc Discharge: Mechanisms of their Production. Japanese Journal of Applied Physics, (1999) 38, L477-L479.

Sugai, T.; Omote, H.; Bandow, S.; Tanaka, N. \& Shinohara, H. (2000). Production of fullerenes and single-wall carbon nanotubes by high-temperature pulsed arc discharge. Journal of Chemical Physics, 112, 6000-6005.

Sugai, T.; Yoshida, H.; Shimada, T.; Okazaki, T. \& Shinohara, H. (2003). New Synthesis of High-Quality Double-Walled Carbon Nanotubes by High-Temperature Pulsed Arc Discharge. Nano Letters, 3, 769-773.

Sun, J.Q.; Wu, T.; Liu, F.; Wang, Z.Q.; Zhang, X. \& Shen, J.C. (2000). Covalently Attached Multilayer Assemblies by Sequential Adsorption of Polycationic Diazo-Resins and Polyanionic Poly(acrylic acid). Langmuir, 16, 4620-4624.

Sun, J.Q.; Wu, T.; Sun, Y.P.; Wang, Z.Q.; Zhang, X.; Shen, J.C. \& Cao, W.X. (1998). Fabrication of a covalently attached multilayer via photolysis of layer-by-layer selfassembled films containing diazo-resins. Chemical Communications, 17, 1853-1854.

Svitel, J.; Surugiu, I.; Dzgoev, A.; Ramanathan, K. \& Danielsson, B. (2001). Functionalized surfaces for optical biosensors: Applications to in vitro pesticide residual analysis. Journal of Materials Science: Materials in Medicine, 12, 1075-1078.

Syu, M.J.; Chiu, T.C.; Lai, C.Y. \& Chang Y.S. (2006). Amperometric detection of bilirubin from a micro-sensing electrode with a synthetic bilirubin imprinted poly(MAA-coEGDMA) film. Biosensors and Bioeletronics, 22, 550-557.

Teles, F.R.R. \& Fonseca, L.P. (2008). Applications of polymers for biomolecule immobilization in electrochemical biosensors. Materials Science and Engineering $C$, $28,1530-1543$.

Thess, A.; Lee, R.; Nikolaev, P.; Dai, H.; Petit, P.; Robert, J.; Xu, C.; Lee, Y.H.; Kim, S.G.; Rinzler, A.G.; Colbert, D.T.; Scuseria, G.E.; Tománek, D.; Fischer, J.E. \& Smalley, R.E. (1996). Crystalline Ropes of Metallic Carbon Nanotubes. Science, 273, 483-487. 
Tian, M.; Bi, W. \& Row, K.H. (2011). Molecular imprinting in ionic liquid-modified porous polymer for recognitive separation of three tanshinones from Salvia miltiorrhiza Bunge. Analytical Bioanalytical Chemistry, 399, 2495-2502.

Updike, S.J \& Hicks, G.P. (1967). The enzyme electrode. Nature, 214, 986-988.

Vaisman, L.,Wagner, H.D. \& Marom, G. (2006). The role of surfactants in dispersion of carbon nanotubes. Advances in Colloid and Interface Science, 128-130, 37-46.

Vasanth Kumar, K.; Monteiro de Castro, M.; Martinez-Escandell, M.; Molina-Sabio, M. \& Rodriguez-Reinoso, F. (2010). A Continuous Binding Site Affinity Distribution Function from the Freundlich Isotherm for the Supercritical Adsorption of Hydrogen on Activated Carbon. Journal of Physical Chemistry C, 114, 13759-13765.

Vasanth Kumar, K.; Monteiro de Castro, M.; Martinez-Escandell, M.; Molina-Sabio, M. \& Rodriguez-Reinoso, F. (2011). A site energy distribution function from Toth isotherm for adsorption of gases on heterogeneous surfaces. Physical Chemistry Chemical Physics, 13, 5753-5759.

Venkatesan, J. \& Kim S.K. (2010). Chitosan Composites for Bone Tissue Engineering - An overview. Marine Drugs, 8, 2252-2266.

Vinjamuri, A.K.; Burns, S.C. \& Dahl, D.B. (2008). Caffeine and Theobromine Selectivity Using Molecularly Imprinted Polypyrrole Modified Electrodes. ECS Transactions, 13, 9-20.

Vyalikh, A.; Wolter, A.U.; Hampel, S.; Haase, D.; Ritschel, M.; Leonhardt, A.; Grafe, H.J.; Taylor, A., Krämer. K.; Büchner, B. \& Klingeler, R. (2008). Nanomedicine, 3: 175-182.

Walcarius, A.; Mandler, D.; Cox, J.A.; Collinson, M. \& Lev, O. (2005). Exciting new directions in the intersection of functionalized sol-gel materials with electrochemistry Journal of Material Chemistry, 15, 3663-3689.

Wang, J. \& Musameh, M. (2003). Carbon Nanotube/Teflon Composite Electrochemical Sensors and Biosensors. Analytical Chemistry, 75, 2075-2079.

Wang, J. \& Musameh, M. (2004). Electrochemical detection of trace insulin at carbonnanotube-modified electrodes. Analytica Chimica Acta, 511, 33-36.

Wang, J.; Li, M.; Shi, Z.; Li, N. \& Gu, Z. (2002). Direct Electrochemistry of Cytochrome c at a Glassy Carbon Electrode Modified with Single-Wall Carbon Nanotubes. Analytical Chemistry, 74, 1993-1997.

Wang, J.; Liu, G. \& Jan, M.R. (2004). Ultrasensitive Electrical Biosensing of Proteins and DNA: Carbon-Nanotube Derived Amplification of the Recognition and Transduction Events. Journal of the American Chemical Society, 126, 3010-3011.

Wang, J.; Musameh, M. \& Lin, Y. (2003). Solubilization of Carbon Nanotubes by Nafion toward the Preparation of Amperometric Biosensors. Journal of the American Chemical Society, 125, 2408-2409.

Wang, J.W.; Khlobystov, A.N.; Wang, W.X.; Howdle, S.M. \& Poliakoff, M. (2006). Coating carbon nanotubes with polymer in supercritical carbon dioxide. Chemical Communications, 15, 1670-1672.

Wang, K.; Xu, J.J.; Tang, K.S. \& Chen, H.Y. (2005). Solid-contact potentiometric sensor for ascorbic acid based on cobalt phthalocyanine nanoparticles as ionophore. Talanta, 67, 798-805.

Wei, Y.; Qiu, L.; Yu, J.C.C. \& Lai, E.P.C.(2007). Molecularly Imprinted Solid Phase Extraction in a Syringe Needle Packed with Polypyrrole-encapsulated Carbon Nanotubes for 
Determination of Ochratoxin A in Red Wine. Food Science and Technology International, 13, 375-380.

Whitcombe, M.J.; Alexander, C. \& Vulfson, E.N. (2000). Imprinted polymers: Versatile new tools in synthesis. Synlett, 911-923.

Whitesides, G.M. (2003). The right size in nanobiotechnology. Nature Biotechnology, 21, 11611165.

Wigthman, R.M. (1988). Voltammetry with Microscopic Electrodes in New Domains. Science, 240, 415-420.

Winey, K.I.; Kasiwagi, T. \& Mu, M. (2007). Improving electrical conductivity and thermal properties of polymers by addition of carbon nanotubes as fillers. MRS Bulletin, 32, 348-353.

Wulff, G. (2002). Enzyme-like catalysis by molecularly imprinted polymers. Chemical Reviews, 102, 1-27.

Xiang, H.Y. \& Li, W.G. (2009). Electrochemical sensor for trans-resveratrol determination based on indium tin oxide electrode modified with molecularly imprinted selfassembled films. Electroanalysis, 21, 1207-1210.

Xie, C.; Gao, S.; Guo, Q. \& Xu, K. (2010) Electrochemical sensor for 2,4-dichlorophenoxy acetic acid using molecularly imprinted polypyrrole membrane as recognition element. Microchimica Acta, 169, 145-152.

Xie, C.; Liu, B.; Wang, Z.; Gao, D.; Guan, G. \& Zhang, Z. (2008). Molecular imprinting at walls of silica nanotubes for TNT recognition. Analytical Chemistry, 80, 437-443.

Xie, C.; Zhang, Z.; Wang, D.; Guan, G.; Gao, D. \& Liu, J. (2006). Surface molecular selfassembly strategy for TNT imprinting of polymer nanowire/nanotube arrays. Analytical Chemistry, 78, 8339-8346.

Xing, B. \& Yin, X.B. (2009). Electrochemiluminescence from hydrophilic thin film $\mathrm{Ru}(\mathrm{bpy}) 3^{2+}$ modified electrode prepared using natural halloysite nanotubes and polyacrylamide gel. Biosensors and Bioelectronics, 24, 2939-2942.

Xu, G.Y.; Wu, W.T.; Wang, Y.S.; Pang, W.M.; Wang, P.H.; Zhu, G.R. \& Lu, F. (2006). Synthesis and characterization of water-soluble multiwalled carbon nanotubes grafted by a thermoresponsive polymer. Nanotechnology, 17, 2458-2465.

Xu, H.X.; Wang, X.B.; Zhang, Y.F. \& Liu, S.Y. (2006). Single-Step in Situ Preparation of Polymer-Grafted Multi-Walled Carbon Nanotube Composites under ${ }^{60} \mathrm{Co} \gamma$-Ray Irradiation. Chemistry of Materials, 18, 2929-2934.

Xu, T.; Zhang, N.; Nichols, H.L.; Shi, D. \& Wen, X. (2007). Modification of nanostructured materials for biomedical applications. Materials Science and Engineering C, 27, 579594.

Yan, D. \& Yang, G. (2009). A novel approach of in situ grafting polyamide 6 to the surface of multi-walled carbon nanotubes. Materials Letters, 63, 298-300.

Yang, B.X.; Pramoda, K.P.; Xu, G.Q. \& Goh, S.H. (2007). Mechanical reinforcement of polyethylene using polyethylene-grafted multiwalled carbon nanotubes. Advanced Functional Materials, 17, 2062-2069.

Yao, Z.; Braidy, N.; Botton, G.A. \& Adronov, A. (2003). Polymerization from the Surface of Single-Walled Carbon Nanotubes - Preparation and Characterization of Nanocomposites. Journal of the American Chemical Society, 125, 16015-16024. 
Ye, L. \& Haupt, K. (2004). Molecularly imprinted polymers as antibody and receptor mimics for assays, sensors and drug discovery. Analytical and Bioanalytical Chemistry, 378, 1887-1897.

Ye, L. \& Mosbach, K. (2001). Molecularly imprinted microspheres as antibody binding mimics. Reactive and Functional Polymers, 48, 149-157.

Yin, J.; Cui, Y.; Yang, G. \& Wang H. (2010). Molecularly imprinted nanotubes for enantioselective drug delivery and controlled release. Chemical Communications, 46, 7688-7690.

You, Y.Z.; Hong, C.Y. \& Pan, C.Y. (2006). Directly growing ionic polymers on multi-walled carbon nanotubes via surface RAFT polymerization. Nanotechnology, 17, 2350- 2354.

$\mathrm{Yu}$, J.C.C. \& Lai, E.P.C. (2006). Molecularly imprinted polypyrrole modified carbon nanotubes on stainless steel frit for selective micro solid phase pre-concentration of ochratoxin A. Reactive and Functional Polymers, 66, 702-711.

Yu, J.C.C. \& Lai, E.P.C. (2007). Determination of ochratoxin A in red wines by multiple pulsed elutions from molecularly imprinted polypyrrole. Food Chemistry, 105, 301310.

Yu, Y.; Ye, L.; Haupt, K. \& Mosbach, K. (2002). Formation of a class of enzyme inhibitors (drugs), including a chiral compound, by using imprinted polymers or biomolecules as molecular-scale reaction vessels. Angewandte Chemie International Edition in English, 114, 4640-4643.

Yurekli, K., Mitchell, C.A. \& Krishnamoorti R. (2004). Small-angle neutron scattering from surfactant-assisted aqueous dispersions of carbon nanotubes. Journal of the American Chemical Society, 126, 9902-9903.

Zeng, H.L.; Gao, C.; Wang, Y.P.; Watts, P.C.P.; Kong, H.; Cui, X.W.; Yan, D.Y. (2006a). In situ polymerization approach to multiwalled carbon nanotubes-reinforced nylon 1010 composites: Mechanical properties and crystallization behavior. Polymer, 47, 113122.

Zeng, H.L.; Gao, C. \& Yan, D.Y. (2006b). Poly(€-caprolactone)-Functionalized Carbon Nanotubes and Their Biodegradation Properties. Advanced Functional Materials, 16, 812- 818.

Zeng, J.; Chen, J.; Chen, W.; Huang, X.; Chen, L. \& Chen, X. (2009). Recent Development of Laboratory-made Solid-phase Microextraction Fibers on the Application of Food Safety Analysis. Food Science and Biotechnology, 18, 579-585.

Zhang, H.; Zhang, Z.; Hu, Y.; Yang, X. \& Yao, S. (2011). Synthesis of a Novel Composite Imprinted Material Based on Multiwalled Carbon Nanotubes as a Selective Melamine Absorbent. Journal of Agricultural and Food Chemsitry, 59, 1063-1071.

Zhang, H.Q.; Ye, L \& Mosbach, K. (2006). Non-covalent molecular imprinting with emphasis on its application in separation and drug development. Journal of Molecular Recognition, 19, 248-259.

Zhang, J.; Wang, Y.; Lv, R. \& Xu, L. (2010). Electrochemical tolazoline sensor based on gold nanoparticles and imprinted poly-o-aminothiophenol film. Electrochimica Acta, 55, 4039-4044.

Zhang, M. \& Gorski, W. (2005). Electrochemical Sensing Based on Redox Mediation at Carbon Nanotubes Analytical Chemistry, 77, 3960-3965. 
Zhang, M.; Huang, J.; Yu, P. \& Chen, X. (2010). Preparation and characteristics of protein molecularly imprinted membranes on the surface of multiwalled carbon nanotubes. Talanta, 81, 162-166.

Zhang, M.N.; Yan, Y.M.; Gong, K.P.; Mao, L.Q.; Guo, Z.X. \& Chen Y. (2004). Electrostatic Layer-by-Layer Assembled Carbon Nanotube Multilayer Film and Its Electrocatalytic Activity for $\mathrm{O}_{2}$ Reduction. Langmuir, 20, 8781-8785.

Zhang, Z.; Hu, Y.; Zhang, H. \& Yao, S. (2010a). Novel layer-by-layer assembly molecularly imprinted sol-gel sensor for selective recognition of clindamycin based on $\mathrm{Au}$ electrode decorated by multi-wall carbon nanotube. Journal of Colloid and Interface Science, 344, 158-164.

Zhang, Z.; Hu, Y.; Zhang, H.; Luo, L. \& Yao, S. (2010b). Layer by layer assembly sensitive electrochemical sensor for selectively probing 1-histidine based on molecular imprinting sol-gel at functionalized indium tin oxide electrode. Biosensors and Bioelectronics, 26, 696-702.

Zhang, Z.; Zhang, H.; Hu, Y. \& Yao, S. (2010c). Synthesis and application of multiwalled carbon nanotubes-molecularly imprinted sol-gel composite material for online solid phase extraction and high performance liquid chromatography determination of trace Sudan IV. Analytica Chimica Acta, 661, 173-180.

Zhang, Z.; Zhang, H.; Hu, Y.; Yang X \& Yao, S. (2010d). Novel surface molecularly imprinted material modified multi walled carbon nanotubes as solid phase extraction sorbent for selective extraction gallium ion from fly ash. Talanta, 82, 304311.

Zhang, Z.H.; Hu, Y.F.; Zhang, H.B.; Luo, L.J. \& Yao, S.Z. (2010). Electrochemical layer-bylayer modified imprinted sensor based on multi-walled carbon nanotubes and solgel materials for sensitive determination of thymidine. Journal of Electroanalytical Chemistry, 644, 7-12.

Zhao, G.C.; Zhang, L.; Wei, X.W. \& Yang, Z.S. (2003). Myoglobin on multi-walled carbon nanotubes modified electrode: direct electrochemistry and electrocatalysis. Electrochemistry Communications, 5, 825-829.

Zhao, H.; Wang, L.; Qiu, Y.; Zhou, Z.; Zhong, W. \& Li, X. (2007). Multiwalled carbon nanotubes as a solid-phase extraction adsorbent for the determination of three barbiturates in pork by ion trap gas chromatography-tandem mass spectrometry (GC/MS/MS) following microwave assisted derivatization. Analytica Chimica Acta, $586,399-406$.

Zhao, X.; Inoue, S.; Jinno, M.; Suzuki, T. \& Ando, Y. (2003). Macroscopic oriented web of single-wall carbon nanotubes. Chemical Physics Letters, 373, 266-271.

Zhao, Y.; Zhang, W.; Chen, H.; Luo, Q. \& Li, S.F.Y. (2002). Direct electrochemistry of horseradish peroxidase at carbon nanotube powder microelectrode. Sensors and Actuators B, 87, 168-172.

Zhou, D.; Yang, L.P.; Yang, R.M.; Song, W.H.; Peng, S.H. \& Wang, Y.M. (2008). Novel quasiinterpenetrating network/ functionalized multi-walled carbon nanotubes doublenetwork composite matrices for DNA sequencing by CE. Electrophoresis, 29, 46374645 .

Zhou, Q.; Wang, W. \& Xiao, J. (2006a). Preconcentration and determination of nicosulfuron, thifensulfuron-methyl and metsulfuron-methyl in water samples using carbon 
nanotubes packed cartridge in combination with high performance liquid chromatography. Analytica Chimica Acta, 559, 200-206.

Zhou, Q.; Xiao, J. \& Wang, W. (2006b). Using multi-walled carbon nanotubes as solid phase extraction adsorbents to determine dichlorodiphenyltrichloroethane and its metabolites at trace level in water samples by high performance liquid chromatography with UV detection. Journal of Chromatography A, 1125, 152-158.

Zhou, Q.; Xiao, J.; Wang, W.; Liu, G.; Shi, Q. \& Wang, J. (2006c). Determination of atrazine and simazine in environmental water samples using multiwalled carbon nanotubes as the adsorbents for preconcentration prior to high performance liquid chromatography with diode array detector. Talanta, 68, 1309-1315.

Zhou, Q.; Xiao, J. \& Wang, W. (2007). Comparison of multiwalled carbon nanotubes and a conventional absorbent on the enrichment of sulfonylurea herbicides in water samples. Analytical Science, 23, 189-192.

Zhou, Y.X.; Yu, B. \& Levon, K. (2003). Potentiometric sensing of chiral amino acids. Chemistry of Materials, 15, 2774-2779. 


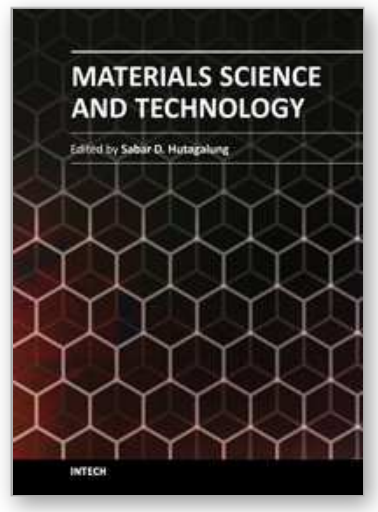

\author{
Materials Science and Technology \\ Edited by Prof. Sabar Hutagalung
}

ISBN 978-953-51-0193-2

Hard cover, 324 pages

Publisher InTech

Published online 07, March, 2012

Published in print edition March, 2012

Materials are important to mankind because of the benefits that can be derived from the manipulation of their properties, for example electrical conductivity, dielectric constant, magnetization, optical transmittance, strength and toughness. Materials science is a broad field and can be considered to be an interdisciplinary area. Included within it are the studies of the structure and properties of any material, the creation of new types of materials, and the manipulation of a material's properties to suit the needs of a specific application. The contributors of the chapters in this book have various areas of expertise. therefore this book is interdisciplinary and is written for readers with backgrounds in physical science. The book consists of fourteen chapters that have been divided into four sections. Section one includes five chapters on advanced materials and processing. Section two includes two chapters on bio-materials which deal with the preparation and modification of new types of bio-materials. Section three consists of three chapters on nanomaterials, specifically the study of carbon nanotubes, nano-machining, and nanoparticles. Section four includes four chapters on optical materials.

\title{
How to reference
}

In order to correctly reference this scholarly work, feel free to copy and paste the following:

Giuseppe Cirillo, Silke Hampel, Francesco Puoci, Diana Haase, Manfred Ritschel, Albrecht Leonhardt, Francesca lemma and Nevio Picci (2012). Carbon Nanotubes - Imprinted Polymers: Hybrid Materials for Analytical Applications, Materials Science and Technology, Prof. Sabar Hutagalung (Ed.), ISBN: 978-953-510193-2, InTech, Available from: http://www.intechopen.com/books/materials-science-and-technology/carbonnanotubes-imprinted-polymers-hybrid-materials-for-analytical-applications

\section{INTECH}

open science | open minds

\section{InTech Europe}

University Campus STeP Ri

Slavka Krautzeka 83/A

51000 Rijeka, Croatia

Phone: +385 (51) 770447

Fax: +385 (51) 686166

www.intechopen.com

\section{InTech China}

Unit 405, Office Block, Hotel Equatorial Shanghai

No.65, Yan An Road (West), Shanghai, 200040, China

中国上海市延安西路65号上海国际贵都大饭店办公楼405单元

Phone: +86-21-62489820

Fax: +86-21-62489821 
(C) 2012 The Author(s). Licensee IntechOpen. This is an open access article distributed under the terms of the Creative Commons Attribution 3.0 License, which permits unrestricted use, distribution, and reproduction in any medium, provided the original work is properly cited. 